\title{
DEVELOPING AND TESTING AN ALKALINE-SIDESGLYENT EXTRACTION PROCESS FOR TECHNETIUM SEPARATION FROM TANK WASTE ${ }^{\mathrm{a}}$
}

\author{
Ralph A. Leonard, Cliff Conner, and Matthew W. Liberatore \\ Argonne National Laboratory \\ Argonne, Illinois 60439-4837 \\ Peter V. Bonnesen, Bruce A. Moyer, and Derek J. Presley \\ Oak Ridge National Laboratory \\ Oak Ridge, Tennessee 37831-6119 \\ and \\ Gregg J. Lumetta \\ Pacific Northwest National Laboratory \\ Richland, Washington 99352
}

Paper for the
Tenth Symposium on Separation Science and Technology for Energy Applications Gatlinburg, Tennessee

October 20-24, 1997

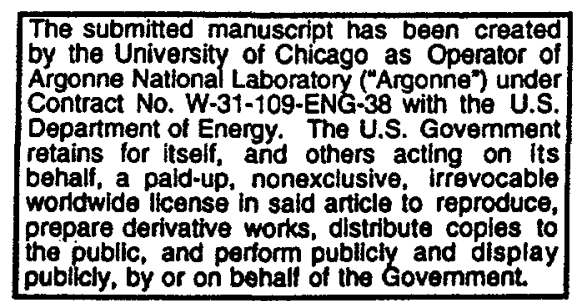

This research was sponsored by the Efficient Separations and Processing Crosscutting Program, Office of Science and Technology, Office of Environmental Management, U.S. Department of Energy under contract number W-31-109-Eng-38 with Argonne National Laboratory and contract number DE-AC05-96OR22464 with Oak Ridge National Laboratory, managed by Lockheed Martin Energy Regearch Corp. 
DEVELOPING AND TESTING AN ALKALINE-SIDE SOLVENT EXTRACTION

PROCESS FOR TECHNETIUM SEPARATION FROM TANK WASTE

\author{
Ralph A. Leonard, Cliff Conner, and Matthew W. Liberatore \\ Argonne National Laboratory \\ Argonne, Illinois 60439-4837 \\ Peter V. Bonnesen, Bruce A. Moyer, and Derek J. Presley \\ Oak Ridge National Laboratory \\ Oak Ridge, Tennessee 37831-6119 \\ and \\ Gregg J. Lumetta \\ Pacific Northwest National Laboratory \\ Richland, Washington 99352
}

\begin{abstract}
Engineering development and testing of the SRTALK solvent extraction process are discussed in this paper. This process provides a way to carry out alkaline-side removal and recovery of technetium in the form of pertechnetate anion from nuclear waste tanks within the DOE complex. The SRTALK extractant consists of a crown ether, bis-4,4'(5) [(tert-butyl)cyclohexano]-18-crown6 , in a modifier, tributyl phosphate, and a diluent, Isopar ${ }^{\circledR} \mathrm{L}$. The SRTALK flowsheet given here separates technetium from the waste and concentrates it by a factor of ten to minimize the load on the downstream evaporator for the technetium effluent. In this work, we initially generated and correlated the technetium extraction data, measured the dispersion number for various processing conditions, and determined hydraulic performance in a single-stage 2$\mathrm{cm}$ centrifugal contactor. Then we used extraction-factor analysis, single-stage contactor tests, and stage-to-stage process calculations to develop a SRTALK flowsheet. Key features of the flowsheet are (1) a low organic-to-aqueous (O/A) flow ratio in the extraction section and a high O/A flow ratio in the strip section to concentrate the technetium and (2) the use of a scrub section to reduce the salt load in the concentrated technetium effluent. Finally, the SRTALK process was evaluated in a multistage test using a synthetic tank waste. This test was very successful. Initial tests with actual waste from the Hanford nuclear waste tanks
\end{abstract}




\section{DISCLAIMER}

This report was prepared as an account of work sponsored by an agency of the United States Government. Neither the United States Government nor any agency thereof, nor any of their employees, make any warranty, express or implied, or assumes any legal liability or responsibility for the accuracy, completeness, or usefulness of any information, apparatus, product, or process disclosed, or represents that its use would not infringe privately owned rights. Reference herein to any specific commercial product, process, or service by trade name, trademark, manufacturer, or otherwise does not necessarily constitute or imply its endorsement, recommendation, or favoring by the United States Government or any agency thereof. The views and opinions of authors expressed herein do not necessarily state or reflect those of the United States Government or any agency thereof. 


\section{DISCLAIMER}

Portions of this document may be illegible in electronic image products. Images are produced from the best available original document. 
show the same technetium extractability as determined with the synthetic waste feed. Therefore, technetium removal from actual tank wastes should also work well using the SRTALK process.

\section{INTRODUCTION}

We are developing and testing a new crown-ether-based process (SRTALK) for alkaline-side solvent extraction of technetium that was invented at Oak Ridge National Laboratory (ORNL) [BONNESEN]. This process is designed to remove and recover technetium in the form of pertechnetate anion from nuclear waste tanks within the DOE complex. Because the SRTALK process works for alkaline waste, it can be applied directly to the waste tank supernate without the need to acidify the solution. In this work, only technetium extraction was evaluated. However, work is continuing on a new SRTALK solvent that will extract $\mathrm{Cs}$, Tc, and possibly, Sr from Hanford tank waste.

The key component of the current SRTALK solvent is the crown ether, bis4,4'(5')[(tert-butyl)cyclohexano]-18-crown-6 (CE_Sr). This crown ether is added to an equal-volume mixture of tributyl phosphate (TBP) and Isopar ${ }^{\circ} \mathrm{L}$ (an isoparaffinic kerosene), which is $1.8 \mathrm{M}$ TBP in Isopar ${ }^{\circledR} \mathrm{L}$. In this work, we evaluated three solvent compositions. The solvent composition used in most tests was $0.04 \underline{\mathrm{M}}$ CE_Sr and 1.8M TBP in Isopar ${ }^{\circ} \mathrm{L}$ (solvent code 4-1). The other two solvent compositions were the same except for the CE_Sr concentration, which was either $0.02 \mathrm{M}$ (solvent code $2-1$ ) or $0.06 \mathrm{M}$ (solvent code $6-1$ ).

The development and testing of the SRTALK flowsheet were done as follows. First, we obtained extraction data for technetium and for other important ions. Second, using the data, we developed a SRTALK flowsheet. Third, we completed a series of single-stage tests in a 2-cm centrifugal contactor ("minicontactor") to evaluate the ability of the contactor to run with the SRTALK solvent. Finally, we carried out a multistage minicontactor test of the SRTALK flowsheet using simulated Hanford tank waste. The discussion of this work 
includes an economic evaluation of the SRTALK process and reports on an initial test of its capability for extracting Tc from actual tank wastes.

\section{EXTRACTION DATA}

Because a crown ether is used to extract the technetium, the SRTALK solvent extracts the pertechnetate anion, $\mathrm{TcO}_{4}$, as a neutral salt with cations such as $\mathrm{Na}^{+}, \mathrm{K}^{+}, \mathrm{Cs}^{+}$, and $\mathrm{Sr}^{2+}$. For DSSF-7, a simulated waste tank feed that approximates double-shell slurry feed (DSSF) of Hanford tank AW-101 [BONNESEN], the distribution ratios between the solvent and this feed for various ions are as follows: $\mathrm{Tc}, 8.6 ; \mathrm{Na}, 0.0011 ; \mathrm{K}, 0.0053 ; \mathrm{Al}, 0.00014 ; \mathrm{NO}_{3}, 0.0028$; and $\mathrm{OH}$, 0.002. The solvent was $0.02 \mathrm{M}$ CE_Sr and $1.8 \mathrm{M}$ TBP in Isopar ${ }^{\circ} \mathrm{L}$ for all ions except Tc, which was done in a solvent with 0.04 Although there will be differences between the two CE_Sr concentrations, it is clear that technetium is extracted to a much higher extent than any of the other anions $\left(\mathrm{AlO}_{2}^{-}, \mathrm{NO}_{3}^{-}\right.$, or $\left.\mathrm{OH}^{-}\right)$.

Tests were done to find out how the distribution ratio for technetium, $\mathrm{D}(\mathrm{Tc})$, varies with the concentration of the various ions in alkaline media at room temperature. These tests showed that $D(T c)$ is a function of the concentration of three ions in the aqueous phase $\left(\mathrm{K}, \mathrm{Na}\right.$, and $\left.\mathrm{NO}_{3}\right)$ as well as the concentration of the crown ether. Based on the data, a correlation for $D(T c)$ as a function of the concentration of $\mathrm{Na}, \mathrm{K}, \mathrm{NO}_{3}$, and $\mathrm{CE} \_\mathrm{Sr}$ in alkaline solutions is given by

$$
\begin{gathered}
D_{T c}=D_{K}+D_{N a}+b_{0} \\
D_{K}=b_{K} x_{K}^{m_{x}} e^{\left(C_{K} x_{N o 3}\right)} \\
D_{N a}=b_{N a} x_{N a}^{m_{N a}} e^{\left(C_{N a} x_{N O 3}\right)} \\
b_{K}=d_{0 . K}+d_{1, K} x_{C E} \\
b_{N a}=d_{0 . N a}+d_{1, N a} x_{C E}
\end{gathered}
$$




$$
\begin{gathered}
b_{0}=e_{0}+e_{1} x_{C E} \\
C_{K}=a_{0}+a_{1} x_{N a}+a_{2} x_{N a}^{2}+a_{3} x_{K}+a_{4} x_{K}^{2}
\end{gathered}
$$

where $a_{0}$ is $-0.52, a_{1}$ is $0.034, a_{2}$ is $0.0009, a_{3}$ is $0.039, a_{4}$ is $-0.1, \mathrm{C}_{\mathrm{Na}}$ is $-0.045, \mathrm{~d}_{0, \mathrm{~K}}$ is 0 , $\mathrm{d}_{1, \mathrm{~K}}$ is $452.5, \mathrm{~d}_{0, \mathrm{Na}}$ is $0.178, \mathrm{~d}_{1, \mathrm{Na}}$ is 20.55, $\mathrm{e}_{0}$ is $0.0015, \mathrm{e}_{1}$ is $0.096, \mathrm{~m}_{\mathrm{K}}$ is 0.82 , and $\mathrm{m}_{\mathrm{Na}}$ is 0.78. Also, $x_{C E}$ is the concentration of CE_Sr, $x_{K}$ is the concentration of $\mathrm{K}, x_{\mathrm{Na}}$ is the concentration of $\mathrm{Na}$, and $\mathrm{x}_{\mathrm{NO} 3}$ is the concentration of nitrate. All concentrations are in units of $\mathrm{mol} / \mathrm{L}$. The empirical model given by this correlation includes data over the range of compositions expected for the aqueous phase in the extraction and scrub sections.

A comparison of the above empirical correlation with the experimental data is shown in Figs. 1-5. The effect of $\mathrm{Na}$ as $\mathrm{NaOH}$ and CE_Sr on $\mathrm{D}(\mathrm{Tc})$ is given in Fig. 1. The effect of $\mathrm{K}$ as $\mathrm{KOH}$ and CE_Sr on $\mathrm{D}(\mathrm{Tc})$ is given in Fig. 2. The effect of

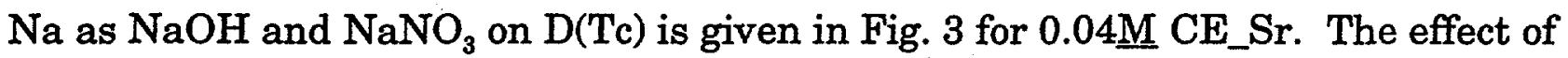
$\mathrm{K}$ as $\mathrm{KOH}$ and $\mathrm{KNO}_{3}$ on $\mathrm{D}(\mathrm{Tc})$ is given in Fig. 4 for 0.04M CE_Sr. The effect of Na, $\mathrm{K}$, and $\mathrm{NO}_{3}$ on $\mathrm{D}(\mathrm{Tc})$ is given in Fig. 5 for $0.04 \underline{\mathrm{M}}$ CE_Sr. The first two figures indicate that $\mathrm{D}(\mathrm{Tc})$ is (1) roughly proportional to the concentration of $\mathrm{CE} \_\mathrm{Sr}$ and (2) an exponential function of the $\mathrm{Na}$ and $\mathrm{K}$ concentrations. The last three figures indicate that $\mathrm{D}(\mathrm{Tc})$ decreases at high nitrate concentrations. Pertechnetate is extracted as $\mathrm{NaTcO}_{4}$ and $\mathrm{KTcO}_{4}$, and nitrate at high concentrations can successfully compete with $\mathrm{TcO}_{4}^{-}$extraction by the extraction of $\mathrm{NaNO}_{3}$ or $\mathrm{KNO}_{3}$. 


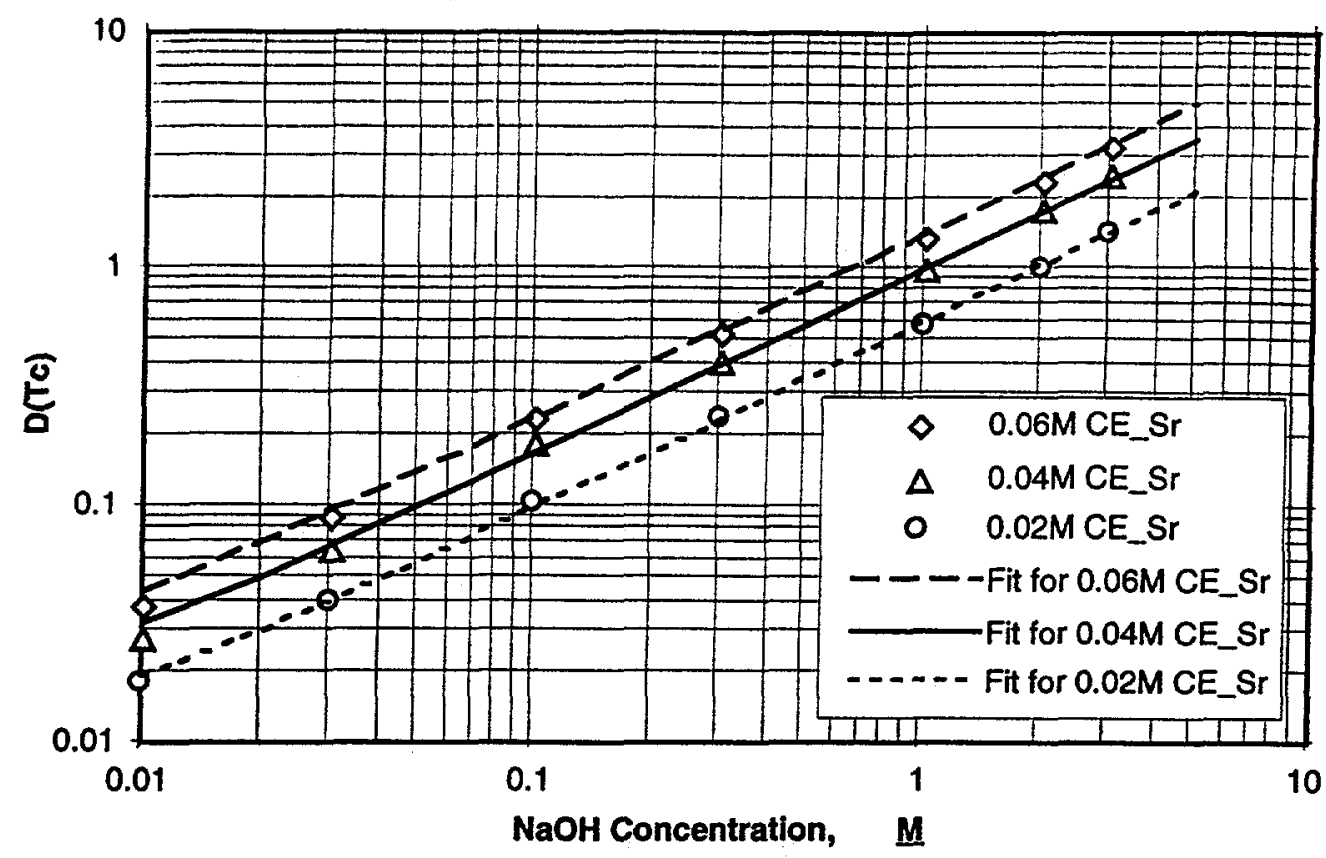

FIGURE 1. Effect of $\mathrm{Na}$ and CE_Sr on the Distribution Ratio for Tc under Alkaline Conditions.

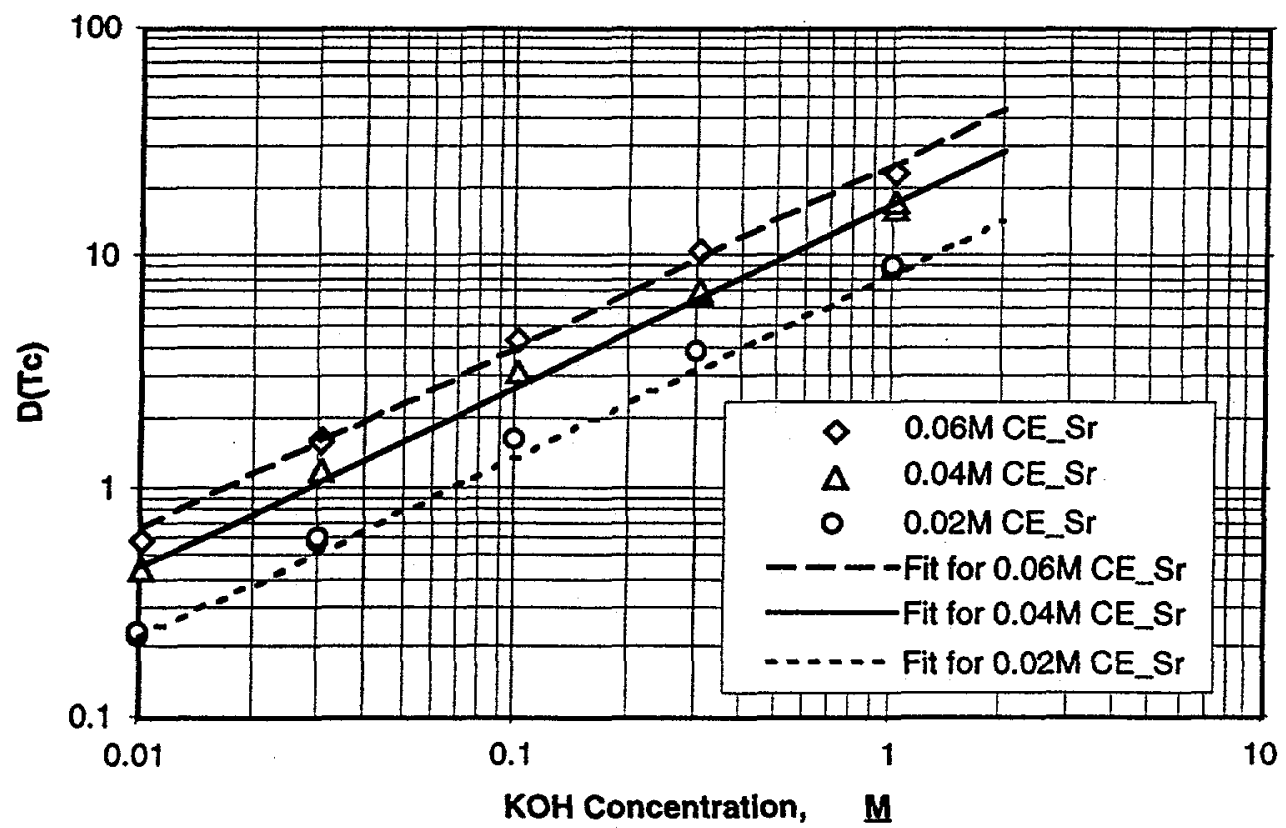

FIGURE 2. Effect of $\mathrm{K}$ and CE_Sr on the Distribution Ratio for Tc under Alkaline Conditions. 


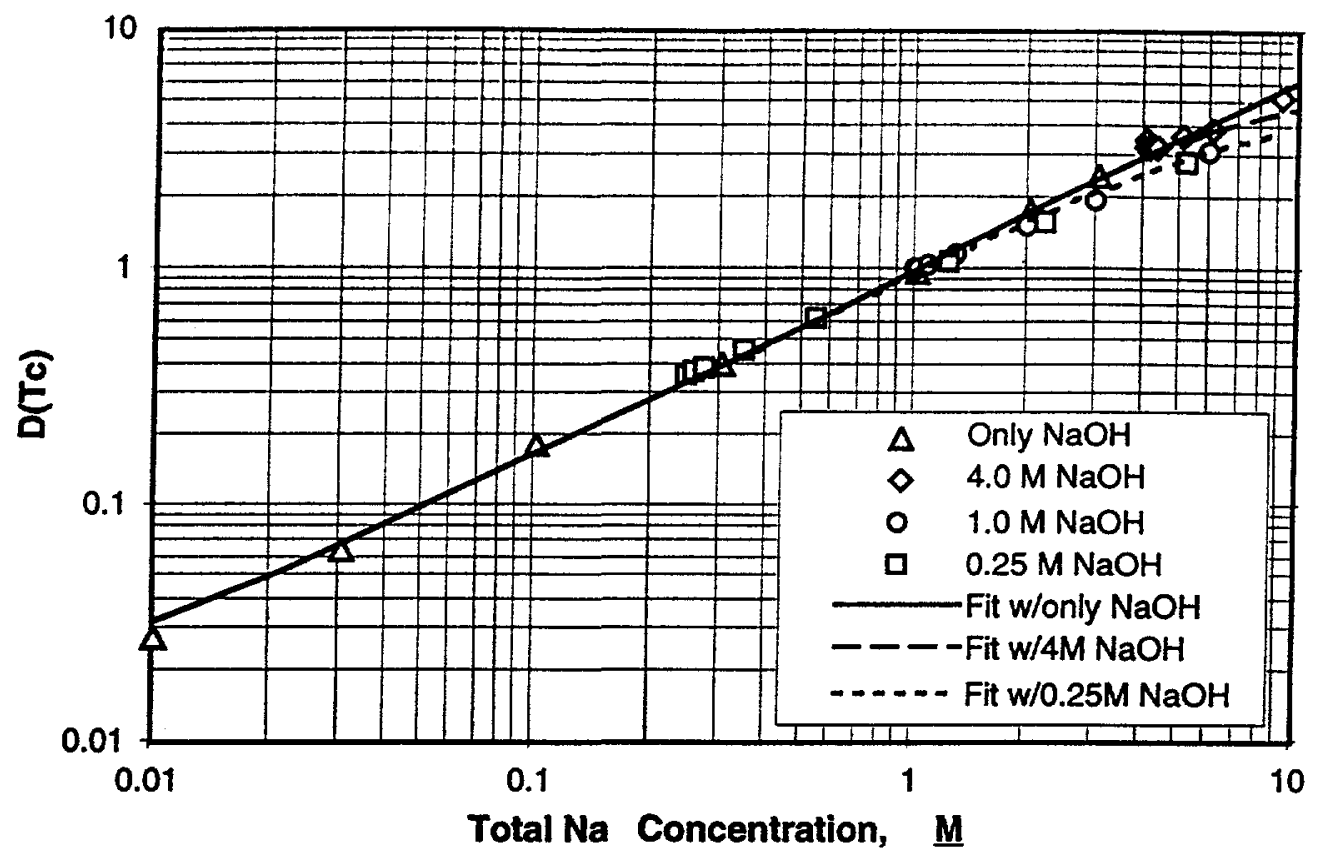

FIGURE 3. Effect of $\mathrm{NaOH}$ and $\mathrm{NaNO}_{3}$ on the Distribution Ratio for Tc under Alkaline Conditions for 0.04M CE_Sr.

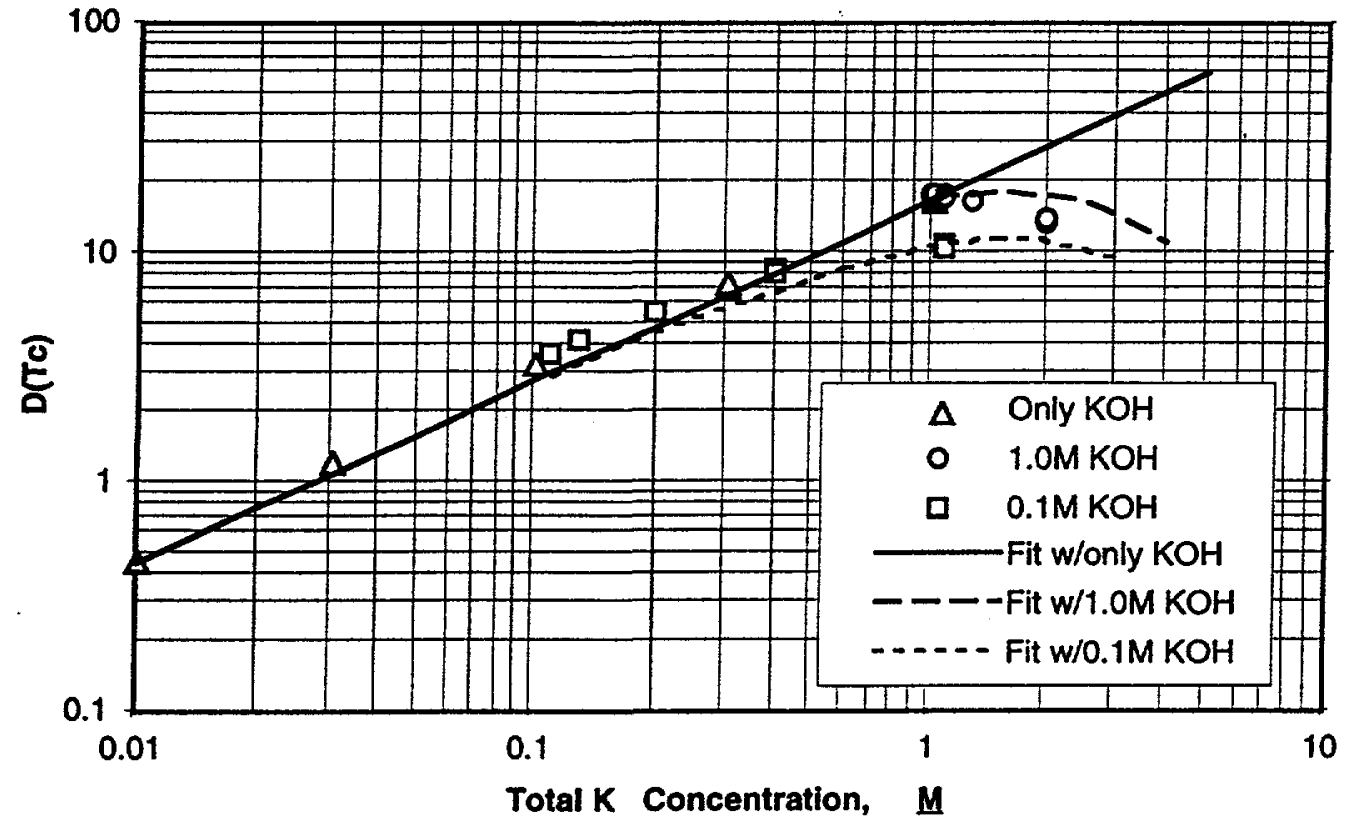

FIGURE 4. Effect of $\mathrm{KOH}$ and $\mathrm{KNO}_{3}$ on the Distribution Ratio for Tc under Alkaline Conditions for 0.04M CE_Sr. 


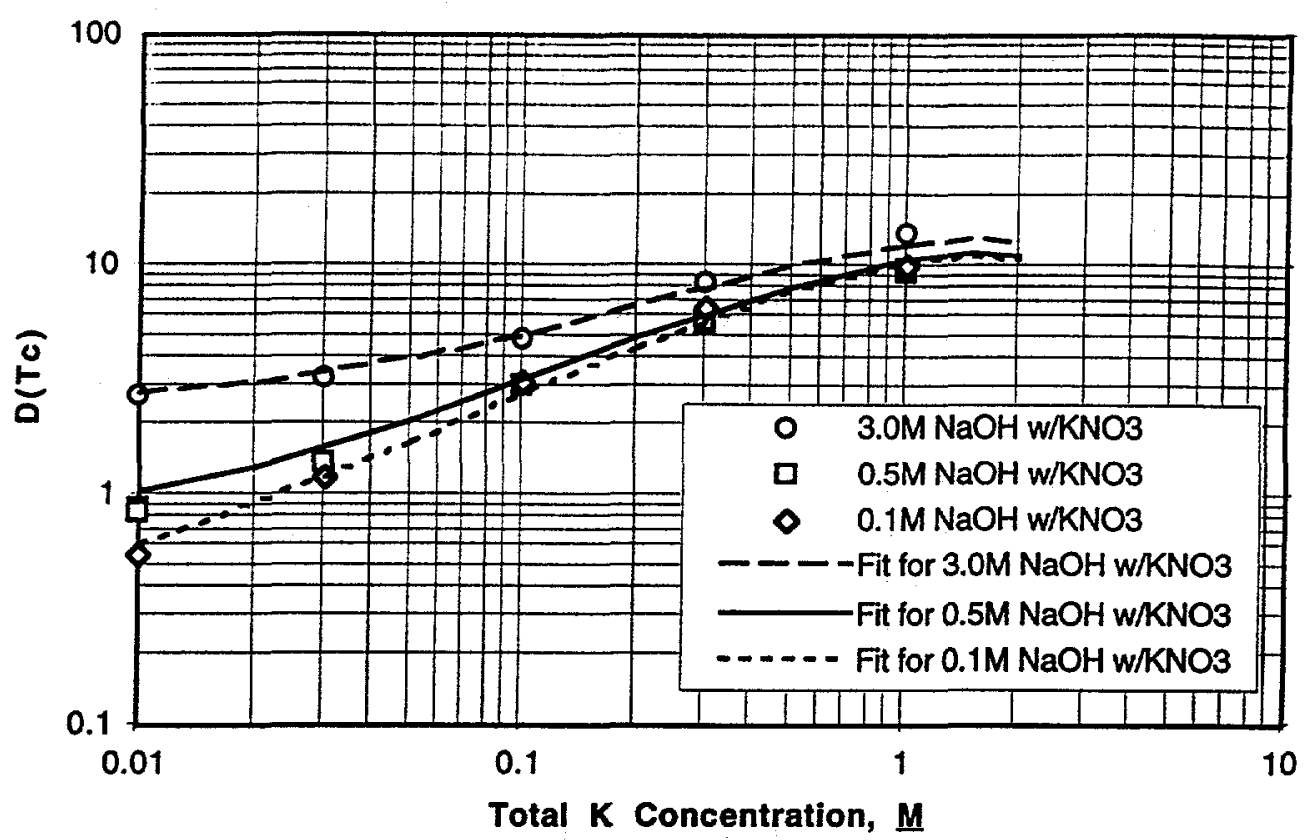

FIGURE 5. Effect of $\mathrm{Na}, \mathrm{K}$, and $\mathrm{NO}_{3}$ on the Distribution Ratio for $\mathrm{Tc}$ under Alkaline Conditions for 0.04M CE_Sr.

Because we planned to operate the strip under slightly acidic conditions, further tests were completed to find out how the distribution ratio for technetium varies with acid and CE_Sr concentrations at room temperature. No metal ions were considered as the scrub section effectively removes them. The tests showed that $\mathrm{D}(\mathrm{Tc})$ was essentially a function of the $\mathrm{HNO}_{3}$ concentration. Based on the data, the empirical correlation for $\mathrm{D}(\mathrm{Tc})$ in acid solutions is

$$
D_{r_{c}}=b_{0}+\frac{f_{0} x}{1+f_{1} x+f_{2} x^{2}}
$$

where $f_{0}$ is $21.6, f_{1}$ is $2.42, f_{2}$ is $3.78, b_{0}$ is given by Eq. (6), and $x$ is the concentration of nitric acid in mol/L. The empirical model given by this correlation includes data over the range of compositions expected for the aqueous phase in the strip section. A comparison of model calculations to the experimental data is shown in Fig 6. That the concentration of CE_Sr has no effect on $\mathrm{D}(\mathrm{Tc})$ indicates that technetium is extracted by the TBP for acid conditions. The shape of the curve is explained as follows. At low concentrations of nitric acid, technetium is extracted 
by TBP as $\mathrm{HTcO}_{4}$. At higher concentrations of nitric acid, TBP is less available as it is tied up as $\mathrm{TBP} \bullet \mathrm{HNO}_{3}, \mathrm{TBP} \bullet\left(\mathrm{HNO}_{3}\right)_{2}$, and $(\mathrm{TBP})_{2} \bullet \mathrm{HNO}_{3}$ species.

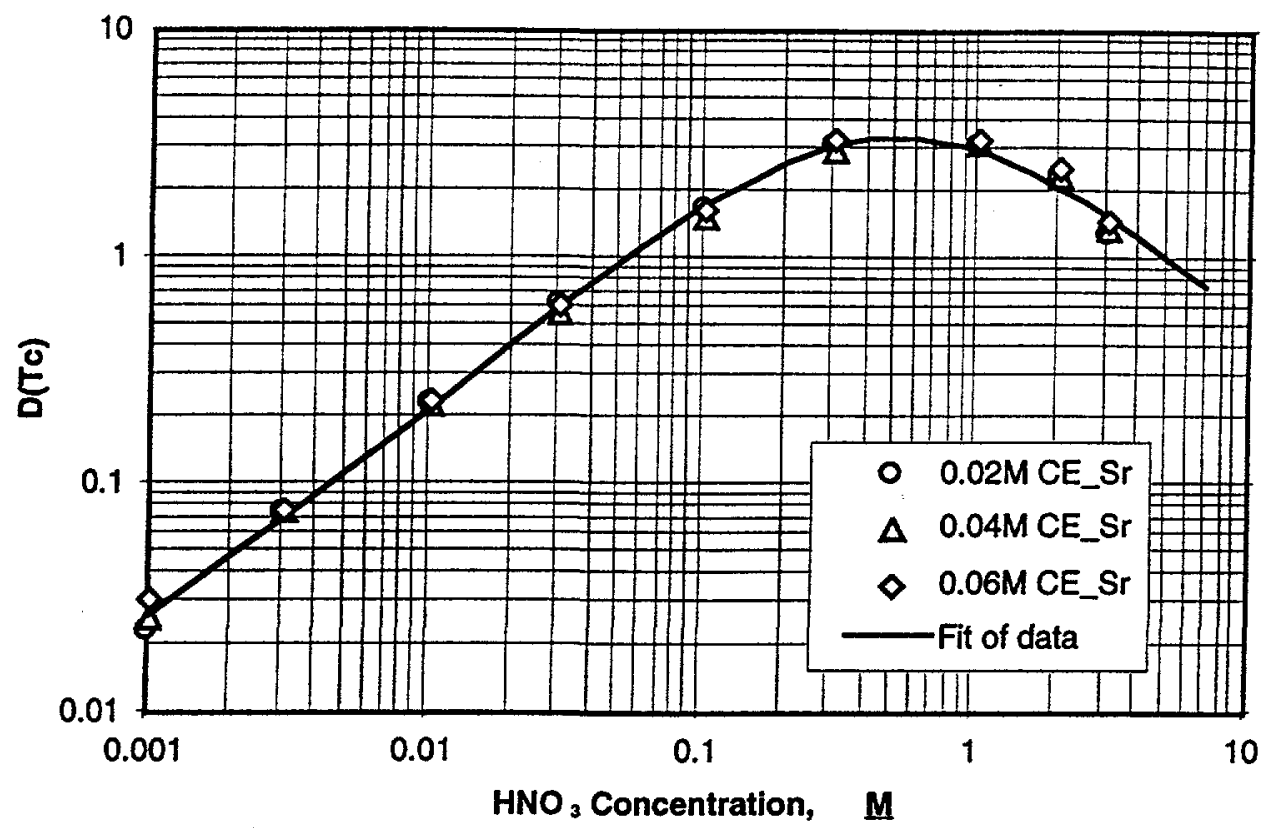
FIGURE 6. Effect of $\mathrm{HNO}_{3}$ and $\mathrm{CE}_{\text {Conditions. }} \mathrm{Sr}$ on the Distribution Ratio for Tc under Acid

\section{FLOWSHEET DEVELOPMENT}

"Using the $\mathrm{D}(\mathrm{Tc})$ correlations above, the process criteria, and an extractionfactor analysis, we developed a flowsheet for testing the SRTALK process. The process criteria were that (1) the required decontamination factor (D.F.) for Tc in the extraction section is only 6.4 [BLANCHARD], (2) the salt carried over into the Tc effluent is minimized, and (3) Tc is concentrated in the Tc effluent. The D.F. for the extraction section is defined as the Tc concentration in the aqueous (DF) feed divided by the Tc concentration in the aqueous (DW) raffinate.

Extraction-factor analysis for solvent extraction, see [LEONARD-1998] or [ROBBINS], uses the extraction factor, E, defined by

$$
E=R D
$$


where $\mathrm{D}$ is the distribution ratio for a given component at a given stage, that is, the concentration of the component in the organic phase, $y$, divided by its concentration in the aqueous phase, $x$; and $R$ is the organic-to-aqueous $(O / A)$ ratio in that stage. The stripping factor is defined as the reciprocal of the extraction factor. In batch countercurrent processes, $R$ is the $O / A$ volume ratio. In continuous countercurrent processes, $R$ is the $\mathrm{O} / \mathrm{A}$ flow ratio. When $\mathrm{E}$ for a given component is greater than 1 , the component will be mainly in the organic phase, and so, most of the component will be carried out in that phase (extraction). When $\mathrm{E}$ is less than 1, the component will be mainly in the aqueous phase, and so, most of the component will be carried out in that phase (stripping). When $\mathrm{E}$ is very close to 1.0 , the component will exit in the effluents of both phases, being somewhat more concentrated in that effluent which is closer to the feed point. For the $\mathrm{D}$ value of a given component, the O/A ratio can be adjusted so that the component is either extracted $(E>1)$ or stripped $(E<1)$. For most practical cases, the $\mathrm{D}$ values should be such that the O/A ratio is in the range from 0.1 to 10 .

In the SRTALK flowsheet, Tc is concentrated in the Tc effluent as follows (determined from extraction-factor analysis). In the extraction section, the O/A ratio ( $R$ value) is made less than 1 so that $T c$ is concentrated in the organic phase. Since $D(T c)$ is about 9 , an $R$ value of 0.33 will still give an $E$ of 3 . In the strip section, the $R$ value is made greater than 1 so that $T c$ is concentrated in the aqueous phase. Since $\mathrm{D}(\mathrm{Tc})$ is about 0.2 , an $\mathrm{R}$ value of 4 will still give an $\mathrm{E}$ of 0.8 . An $R$ value of 2 in the scrub section minimizes the additional volume to the aqueous raffinate. Using these $R$ values, we found that $T c$ will be concentrated by a factor of 10 in the Tc effluent compared to the feed concentration. With this flowsheet (Fig. 7), the D.F. and the decontamination factor for the strip section (S.F.) will both be greater than 6.4, and the two-stage scrub section will keep the salt concentration in the Tc effluent low. Because the flowsheet was designed to concentrate $\mathrm{Tc}$, the extraction and stripping factors for $\mathrm{Tc}$ are close to 1.0 and thus require more stages to get the desired D.F. and S.F. In this case, we used five extraction stages and five strip stages. If there were no need to concentrate $\mathrm{Tc}$ in its effluent, then three extraction stages and three strip stages would have been sufficient. 


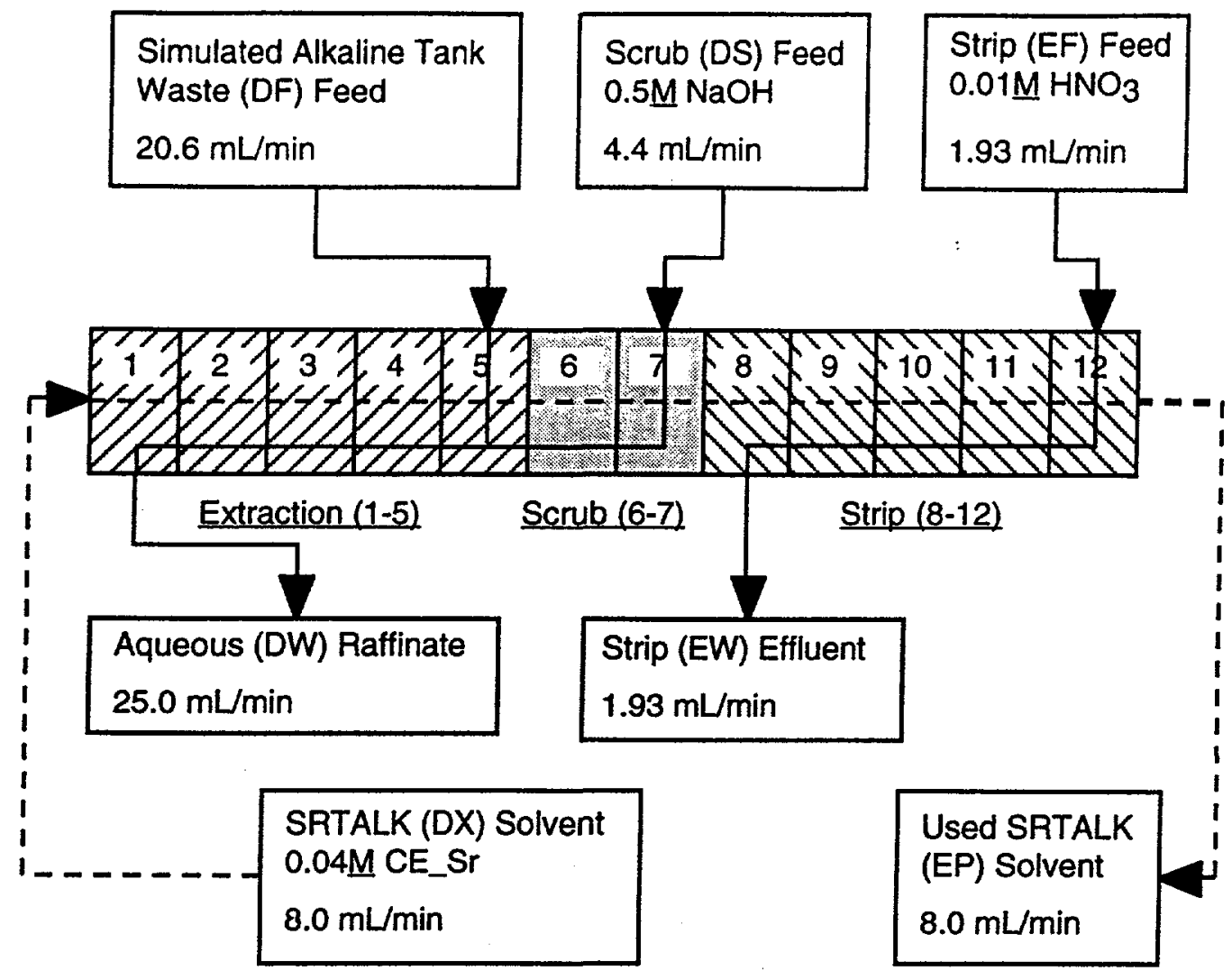

FIGURE 7. SRTALK Flowsheet for Multistage Contactor Test (Test SK1).

The scrub section removes all of the metal salts except Tc from the solvent. However, the removal of $\mathrm{Na}$ is limited by the $\mathrm{NaOH}$ concentration in the scrub (DS) feed. After two scrub stages, the concentration of all other metal ions except Tc in the strip (EW) effluent will be much lower than Na. Since the scrub (DS) feed is introduced at the last scrub stage, more scrub stages would have almost no effect on the concentration of $\mathrm{Na}$ carried over to the strip section. Thus, the $\mathrm{NaOH}$ concentration in the scrub feed should be made as low as possible. However, it should not be made so low that pinching of $\mathrm{Tc}$ in the scrub section is a problem. (Pinching of Tc occurs when Tc, which is extracted in the extraction section, is stripped in the scrub section. The more the stripping, the greater the pinching.) Using the SASSE worksheet [LEONARD-1994] with the alkaline D(Tc) correlation above to evaluate the SRTALK flowsheet, we determined that a $\mathrm{NaOH}$ concentration of $0.5 \mathrm{M}$ gives a good balance between minimizing $\mathrm{Tc}$ pinching in the scrub section and minimizing $\mathrm{Na}$ salt in the $\mathrm{Tc}$ effluent. In general, pinching of components should be avoided. However, some pinching of the Tc will be 
acceptable as long as (1) its scrub-section concentration is not so high that precipitates form or the section takes a long time to reach steady state, and (2) more extraction stages are added to keep the Tc concentration in the aqueous (DW) raffinate low.

Sufficient acid is needed in the strip (EF) feed to neutralize any base that might be carried over with the solvent from the scrub section. To achieve this, the $\mathrm{HNO}_{3}$ concentration in the strip (EF) feed was set at $0.01 \mathrm{M}$. The two-stage scrub section with its $0.5 \mathrm{M} \mathrm{NaOH}$ feed should keep most of the base out of the strip section. This will be the case if aqueous-phase carryover is low in the solvent as it goes from the scrub section to the strip section.

To test this SRTALK flowsheet, the feed compositions were planned to be as follows. The DX feed was solvent 4-1; DS was $0.5 \underline{\mathrm{M} \mathrm{NaOH}} \mathrm{EF}$ was $0.01 \mathrm{M} \mathrm{HNO}_{3}$; and DF was $4.5 \underline{\mathrm{M} \mathrm{NaOH}}, 0.5 \underline{\mathrm{M}} \mathrm{NaNO}_{3}, 0.5 \underline{\mathrm{M}} \mathrm{KNO}_{3}, 0.5 \underline{\mathrm{M} \mathrm{Al}}\left(\mathrm{NO}_{3}\right)_{3}$, and a small amount of $\mathrm{TcO}_{4}^{-}\left(6 \times 10^{-5} \mathrm{M}\right)$. The composition for the simulated (DF) waste feed was based on (1) the composition of NCAW and DSSF-7 waste tank supernates [BONNESEN], (2) the assumption that the tank waste would be diluted until $\mathrm{Na}$ was only $5 \underline{M}$, and (3) a knowledge of which ions affect pertechnetate extraction. The feed flow rates and most feed compositions are shown in Fig. 7. The composition of the aqueous (DF) feed is given in Table 1.

TABLE 1. Measured Component Concentrations in the Aqueous (DF) Feed and the Strip (EW) Effluent at the End of SRTALK Test SK1

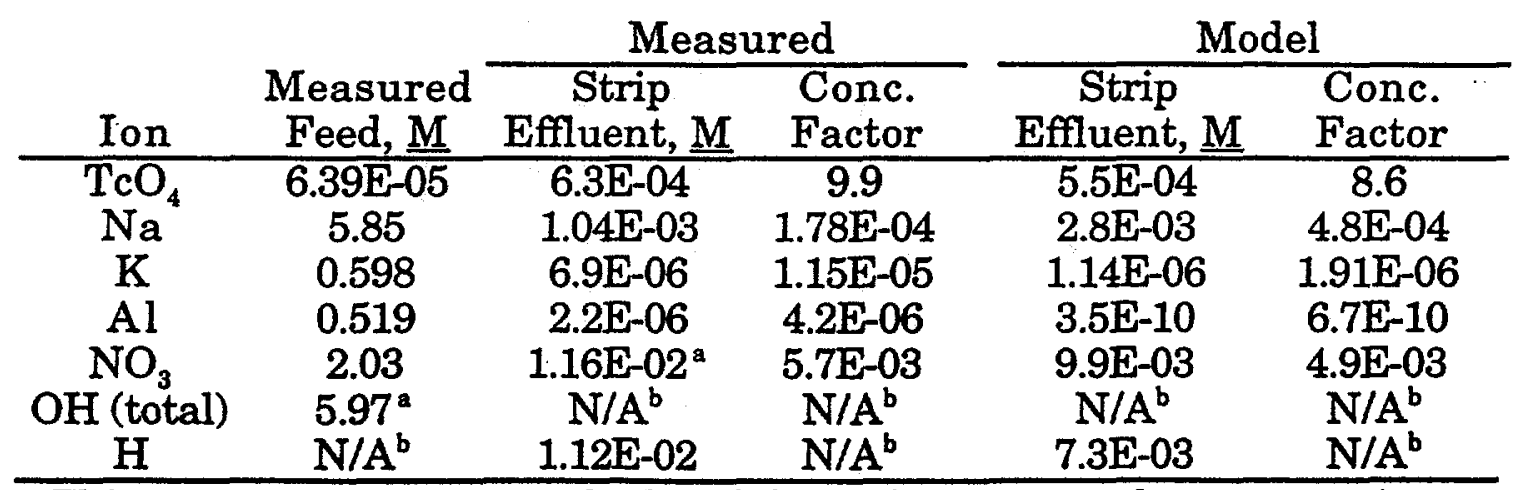

a This concentration was calculated from the measured concentrations of the other ions present in this feed or effluent.

${ }^{\mathrm{b}} \mathrm{N} / \mathrm{A}=$ Not applicable. 


\section{SINGLE-STAGE TESTS}

To verify that the SRTALK flowsheet shown in Fig. 7 could be carried out in a centrifugal contactor [LEONARD-1997] or other solvent-extraction equipment, we had to determine if the contactor would be operable over the range of conditions to be encountered. These questions were addressed in (1) dispersion-number tests that predict hydraulic performance in the centrifugal contactor, (2) single-stage contactor tests that measure hydraulic performance directly, and (3) single- and four-stage contactor tests that measure stage efficiency by mass transfer.

\section{Dispersion Number}

Tests that measure the dimensionless dispersion number, N(Di), allow one to quickly determine the operating characteristics that should be expected during solvent extraction, specifically the ability of the organic and aqueous phases to separate after being mixed together [LEONARD-1995]. By performing dispersionnumber tests in graduated cylinders before the one-stage hydraulic-performance tests in the centrifugal contactor, one can assess the general operating characteristics of the process over the expected range of flowsheet conditions. In this way, the number of contactor tests can be greatly reduced and focused on possible problem areas. In our gravity-settling tests to measure $\mathrm{N}(\mathrm{Di})$, we used the 100-mL graduated-cylinder test described by [LEONARD-1995]. Based on the SRTALK flowsheet shown in Fig. 7, all dispersion numbers were measured at three $\mathrm{O} / \mathrm{A}(\mathrm{R})$ volume ratios, $0.33,1$, and 3 . The aqueous phase concentrations were 0.01 and $1 \mathrm{M} \mathrm{HNO}_{3} ; 0.01,0.1$, and $1 \mathrm{M} \mathrm{NaOH} ; 0.01 \mathrm{M} \mathrm{NaNO}_{3}$; and $0.01 \mathrm{M}$ $\mathrm{NaNO}_{3}$ with 0.01 and $0.1 \mathrm{M} \mathrm{NaOH}$. For most tests, the solvent was 4-1. For the $0.1 \mathrm{M} \mathrm{NaOH}$ test, the most extreme operating regime for the solvent in the proposed SRTALK flowsheet, the 2-1 and 6-1 solvents were also tested. To quantify the separation performance for the various aqueous-organic pairs, a rating system was selected so that "excellent" or " $\mathrm{E}$ " means $\mathrm{N}(\mathrm{Di})>16 \times 10^{-4}$, "very good" or "VG" means $N(D i)$ is 8 to $16 \times 10^{-4}$, "good" or "G" means $N(D i)$ is 4 to $8 \times 10^{-4}$, "fair" or "F" means $\mathrm{N}(\mathrm{Di})$ is 2 to $4 \times 10^{-4}$, "poor" or " $\mathrm{P}$ " means $\mathrm{N}(\mathrm{Di})$ is 0.2 to $2 \times 10^{-4}$, and "very poor" or "VP" means that $\mathrm{N}(\mathrm{Di})<0.2 \times 10^{-4}$. 
From the results of the dispersion-number tests, the following observations were made. The ability of all three solvents to separate improves as the CE_Sr concentration decreases, going from $P / G$ for 6-1, to F/G for 4-1 and G/VG for 2-1. The $\mathrm{NaNO}_{3}$-alone and the $\mathrm{HNO}_{3}$ tests ranged from $\mathrm{F}$ to $\mathrm{E}$, with most results being VG. When $\mathrm{NaNO}_{3}$ was combined with $\mathrm{NaOH}$, the mixture took on the performance characteristic of $\mathrm{NaOH}$ alone. The $\mathrm{NaOH}$ solutions had a more variable separation performance. The $1 \mathrm{M} \mathrm{NaOH}$ tests ranged from $\mathrm{G}$ to VG except at $R=3$, which was $P$. The $0.1 \underline{\mathrm{M}} \mathrm{NaOH}$ tests ranged from $\mathrm{F}$ to $\mathrm{G}$. The $0.01 \mathrm{M}$ $\mathrm{NaOH}$ tests were VP except at $\mathrm{R}=3$, which was $\mathrm{F}$ to $\mathrm{G}$. From the cloudiness of the separated phases in the dispersion-number test, it appeared that the aqueous (DW) raffinate would be hazy for the flowsheet shown in Fig. 7, and the strip (EW) effluent would be crystal clear.

Based on the results of the dispersion-number tests, the flowsheet shown in Fig. 7 should work well. The tests point out a potential problem if the concentration of $\mathrm{NaOH}$ in the $\mathrm{DS}$ feed goes below $0.1 \mathrm{M}$. However, this will not be done as it would cause severe pinching of the $\mathrm{Tc}$ in the scrub section. A second potential problem area is high base concentrations at high $R$ values. However, this condition is outside the planned operating regime for the SRTALK flowsheet, as low $R$ values will be used to enhance Tc concentration in the extraction section.

\section{Hydraulic Performance}

Single-stage hydraulic-performance tests were completed in a 2-cm contactor ("minicontactor"). The experimental conditions were essentially the same as used for the dispersion-number tests; only the $\mathrm{NaNO}_{3}$ plus $\mathrm{NaOH}$ tests were omitted. All tests were conducted at a total throughput of $40 \mathrm{~mL} / \mathrm{min}$, which is the nominal throughput of the minicontactor based on a $N(\mathrm{Di})$ of $8 \times 10^{-4}$.

The following observations were made from the hydraulic-performance tests. Most of the tests showed very good performance with complete phase separation and no detectable other-phase carryover in a 40-mL centrifuge tube, that is, $<0.025 \% \mathrm{~A}$ in $\mathrm{O}$ or $<0.25 \% \mathrm{O}$ in $\mathrm{A}$. The only test where we found unacceptable other-phase carryover, that is, $>1 \% \mathrm{~A}$ in $\mathrm{O}$ or $\mathrm{O}$ in $\mathrm{A}$, was at $0.01 \mathrm{M}$ 
$\mathrm{NaOH}$. For this aqueous phase, other-phase carryover was as high as $13 \%$ for $R=0.33,16 \%$ for $R=1$, and $1.3 \%$ for $R=3$. From the cloudiness of the separated phases, it appears that the aqueous (DW) raffinate would be hazy for the flowsheet shown in Fig. 7, and the strip (EW) effluent would be slightly hazy. During these tests, it was determined that a cloudy effluent corresponds to about $400 \mathrm{ppm}$ $(0.04 \%)$ of other-phase carryover and that a hazy effluent corresponds to about 20 ppm (0.002\%) of other-phase carryover. The $400-\mathrm{ppm}$ measurement was made for the aqueous phase in an organic effluent by measuring the aqueous-phase volume after it had settled out. The 20 -ppm measurement was made for the organic phase in an aqueous effluent by measuring the organic-phase volume after it had all floated to the surface. The organic volume was measured by pouring the two separated phases into a stainless-steel pan filled with water and observing the diameter and thickness of the organic film on the surface.

Based on the results of the hydraulic-performance tests, the flowsheet shown in Fig. 7 should work well. The hydraulic-performance tests show even better operation than the dispersion-number tests. This is attributed to some additional benefit as the centrifugal force drives the dispersed droplets to their bulk phase in a more rapid fashion than is predicted by the dispersion number. These tests also confirm that a problem will occur for concentrations of $\mathrm{NaOH}$ in the DS feed below 0.1M. Since $A$ in $O$ carryover is very low, the small amount of $0.5 \mathrm{M} \mathrm{NaOH}$ that is carried over from the scrub section into the strip section will not be enough to neutralize the dilute $\mathrm{HNO}_{3}$ there, even with the high O/A flow ratio of the strip section.

\section{Stage Efficiency}

To evaluate the mass-transfer efficiency of the centrifugal contactor with respect to extraction of technetium by crown ether under alkaline conditions, single-stage minicontactor tests were done over a range of conditions. Based on earlier work with contactors [LEONARD-1997], stage efficiency was expected to be very high, close to $100 \%$, for Tc in the SRTALK process. Except where noted, all tests were made with a total throughput of $40 \mathrm{~mL} / \mathrm{min}$, an $\mathrm{O} / \mathrm{A}$ flow ratio of 1.0 , an 
aqueous (DF) feed of the composition shown in Fig. 7, and the solvent 4-1 that was recovered from a SRTALK flowsheet test (designated SK1) and cleaned up by using dilute nitric acid in a four-stage test (SK2). The $63.9 \mu \mathrm{M} \mathrm{Tc}$ in the DF feed was mostly ${ }^{99} \mathrm{Tc}$ with a spike of ${ }^{99 \mathrm{~m}} \mathrm{Tc}$. This allowed $\mathrm{Tc}$ to be measured first by gamma counting and then by liquid-scintillation counting. The agreement between these two methods was very good.

The extraction or stage efficiency is defined as the amount of Tc that is transferred from one phase to the other relative to the amount that would have been transferred if the two phases were in equilibrium [LEONARD-1987]. For each of the one-stage tests, the equilibrium $D(T c)$ value was obtained by equilibrating the feed solutions at the same O/A volume ratio and temperature as the effluent streams. Thus, the stage efficiencies for these one-stage tests were independent of the empirical correlation for $\mathrm{D}(\mathrm{Tc})$ given in Eqs. (1-8).

The results of the stage-efficiency tests are as follows. The first three tests, SK3 through SK5, used solvents 2-1, 6-1, and 4-1, respectively, and evaluated the effect of CE_Sr concentration on stage efficiency. As shown in Fig. 8, the stage efficiency was essentially $100 \%$. The tests SK5, SK6, and SK7 examined the effect of O/A flow ratio on stage efficiency. As shown in Fig. 9, the stage efficiency was essentially $100 \%$ except for $R=0.33$, where it dropped to $92 \pm 2 \%$. The tests SK5, SK8, and SK9 ascertained the effect of throughput on stage efficiency. As shown in Fig. 10, the stage efficiency was essentially $100 \%$ for all three cases. The tests SK10 and SK11 approximated the scrub section of the SRTALK flowsheet with $R=2$, a total throughput of $30 \mathrm{~mL} / \mathrm{min}$, and an aqueous feed of $0.5 \mathrm{M} \mathrm{NaOH}$. The organic feed for SK10 was the combined organic phase collected from tests SK5 through SK9. The organic effluent from SK10 was the organic feed for SK11. The stage efficiencies were harder to measure for these two tests since only a small fraction of the Tc in the organic phase was transferred back into the aqueous phase. However, the stage efficiency appears to be essentially $100 \%$, with $108 \pm 4 \%$ for SK10 and $93 \pm 7 \%$ for SK11. The final test, SK12, approximated the strip section with $\mathrm{R}=3$, an aqueous feed of $0.01 \mathrm{M} \mathrm{HNO}_{3}$, and the organic effluent from SK11 as the organic feed for SK12. Because the contactor stage had not been drained after 
SK11, SK12 was not at full steady-state conditions and experimental errors were large. However, the stage efficiency for SK12 was probably close to $100 \%$, with a measured value of $88 \pm 11 \%$.

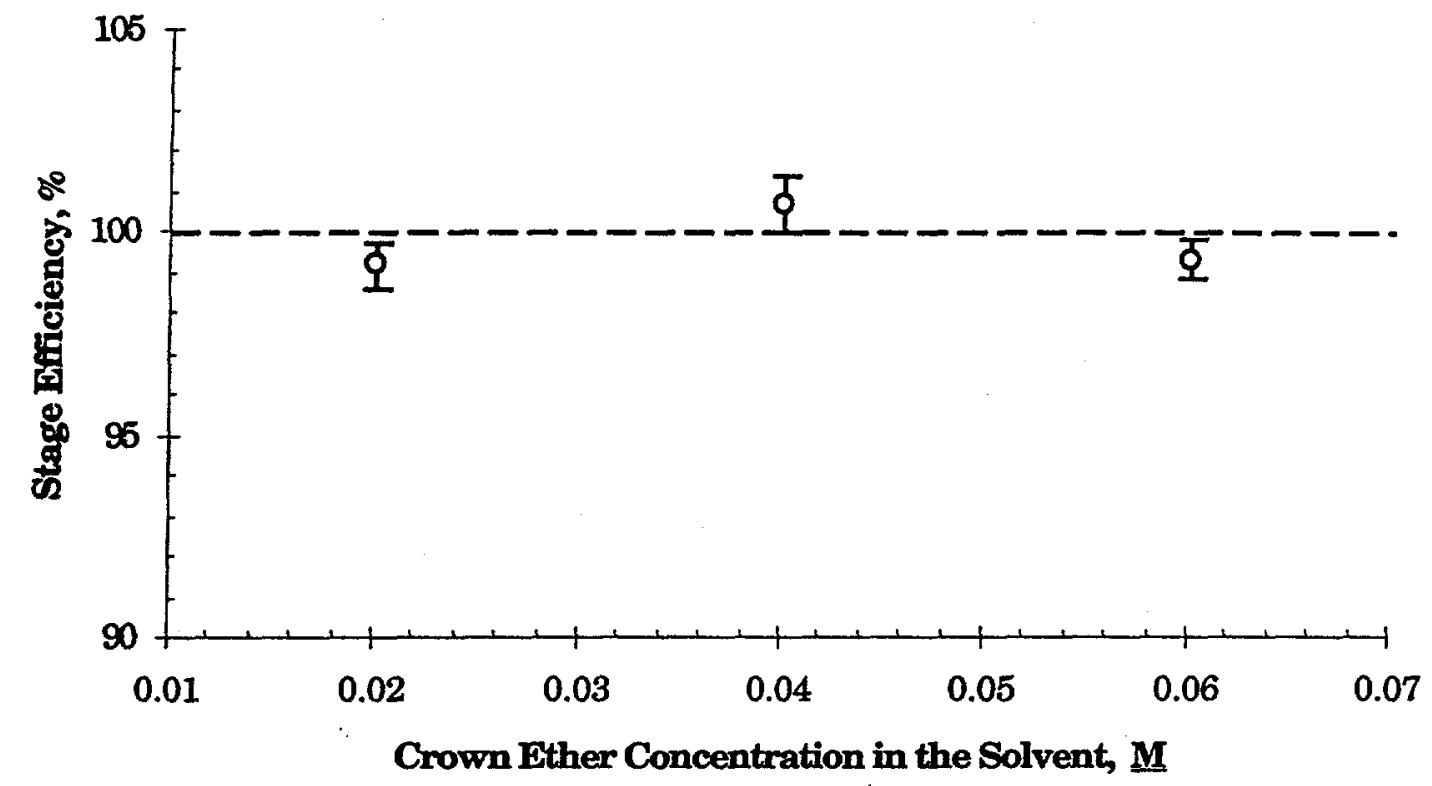

FIGURE 8. Effect of Crown Ether Concentration on Stage Efficiency for the Minicontactor.

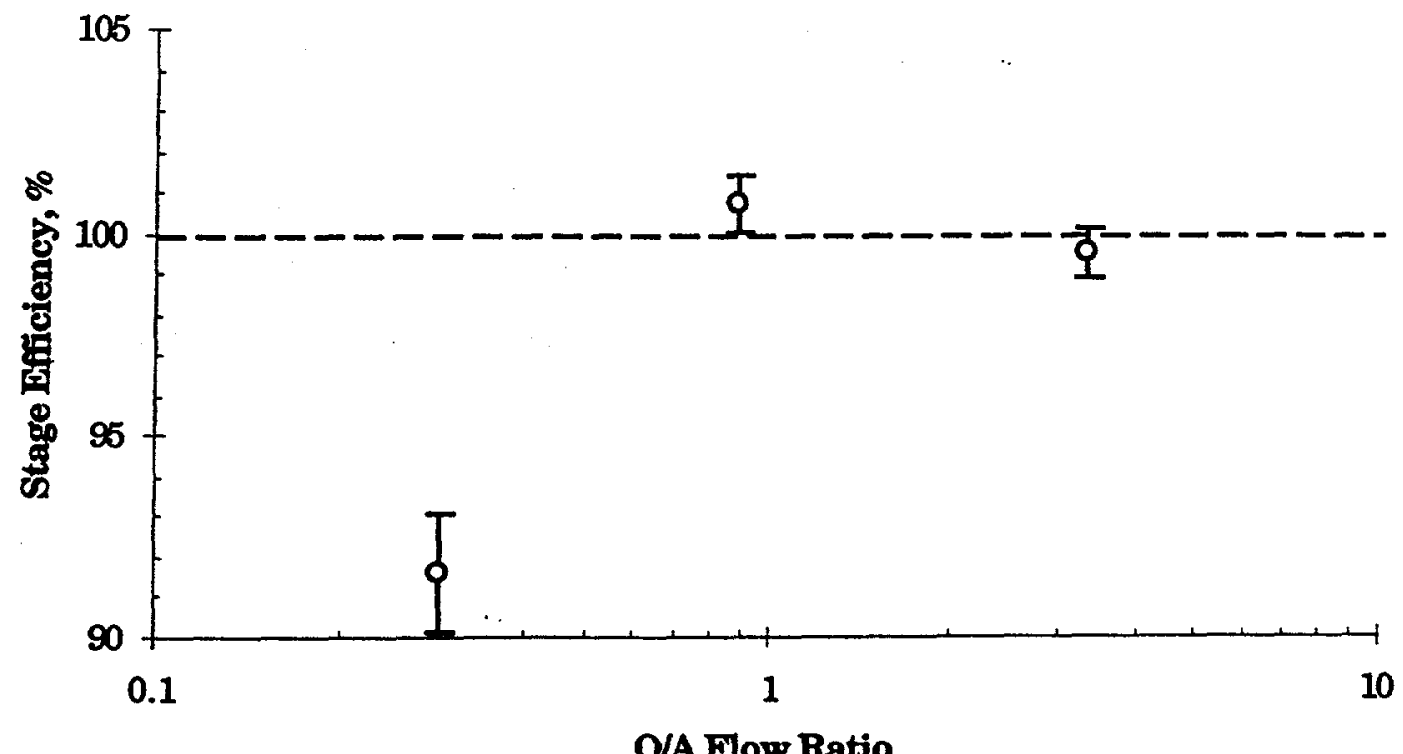

FIGURE 9. Effect of O/A Flow Ratio on Stage Efficiency for the Minicontactor. 


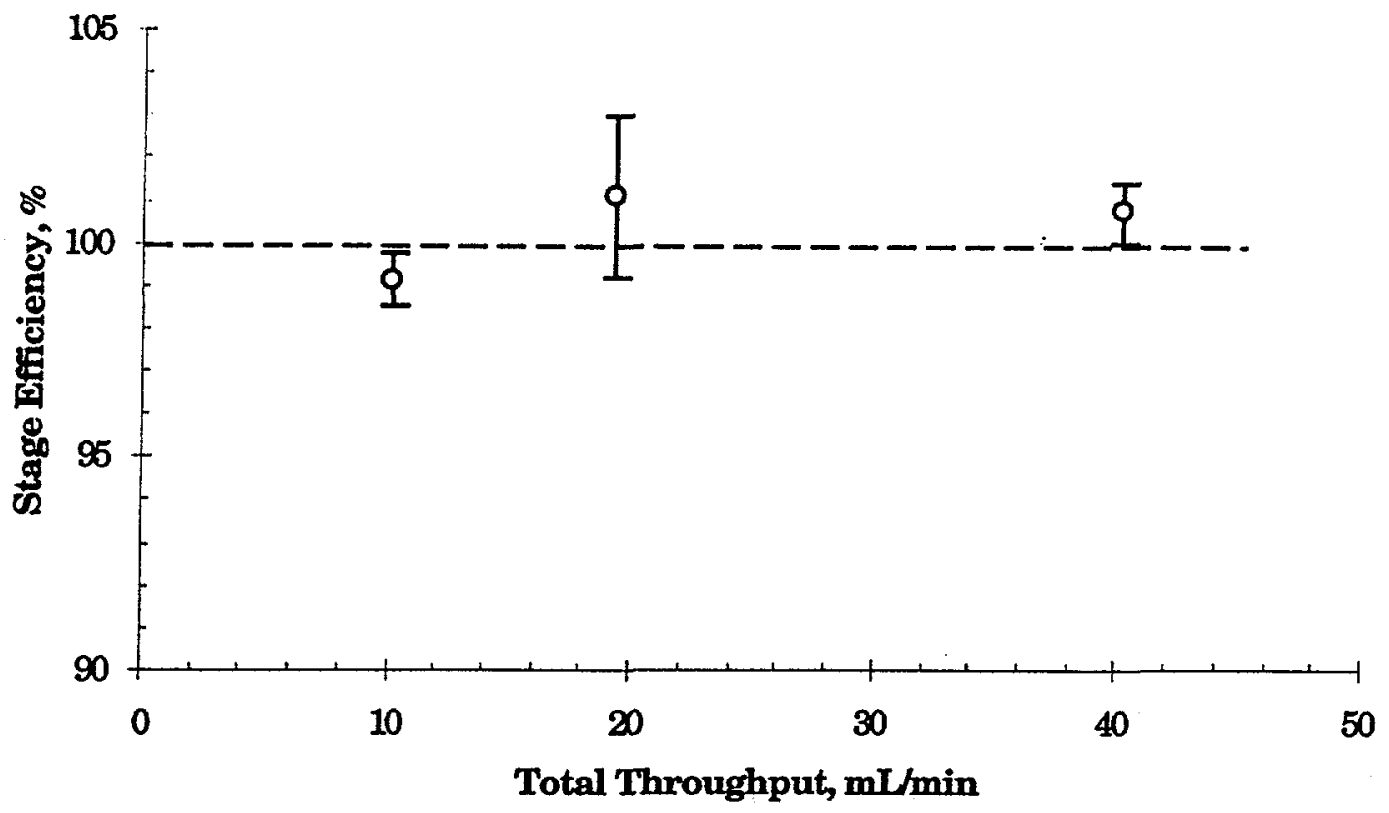

FIGURE 10. Effect of Total Throughput on Stage Efficiency for the Minicontactor.

In addition to the one-stage mass-transfer tests, the average stage efficiency was measured for one four-stage test, which was done as a part of the solvent cleanup for the SRTALK flowsheet test (SK1) discussed below. The flowsheet for this four-stage test (SK2) is shown in Fig. 11. Because the contactor had been flushed with $1 \mathrm{M} \mathrm{HNO}_{3}$ and drained before the test, the acid in the DW raffinate was higher than expected and decreased slowly with time. During the masstransfer test, which was done $60 \mathrm{~min}$ after startup, the $\mathrm{DW}$ raffinate was $0.173 \mathrm{M}$ $\mathrm{HNO}_{3}$. Based on the relative distribution of $\mathrm{Tc}$ between the aqueous and organic effluents and the $D(T c)$ correlation in Eq. (8), SASSE calculations showed the average stage efficiency was $91 \pm 2 \%$. Since this test had an O/A flow ratio of 0.33 , this four-stage result confirms the one-stage result that operation at low O/A flow ratios gives lower stage efficiencies. 


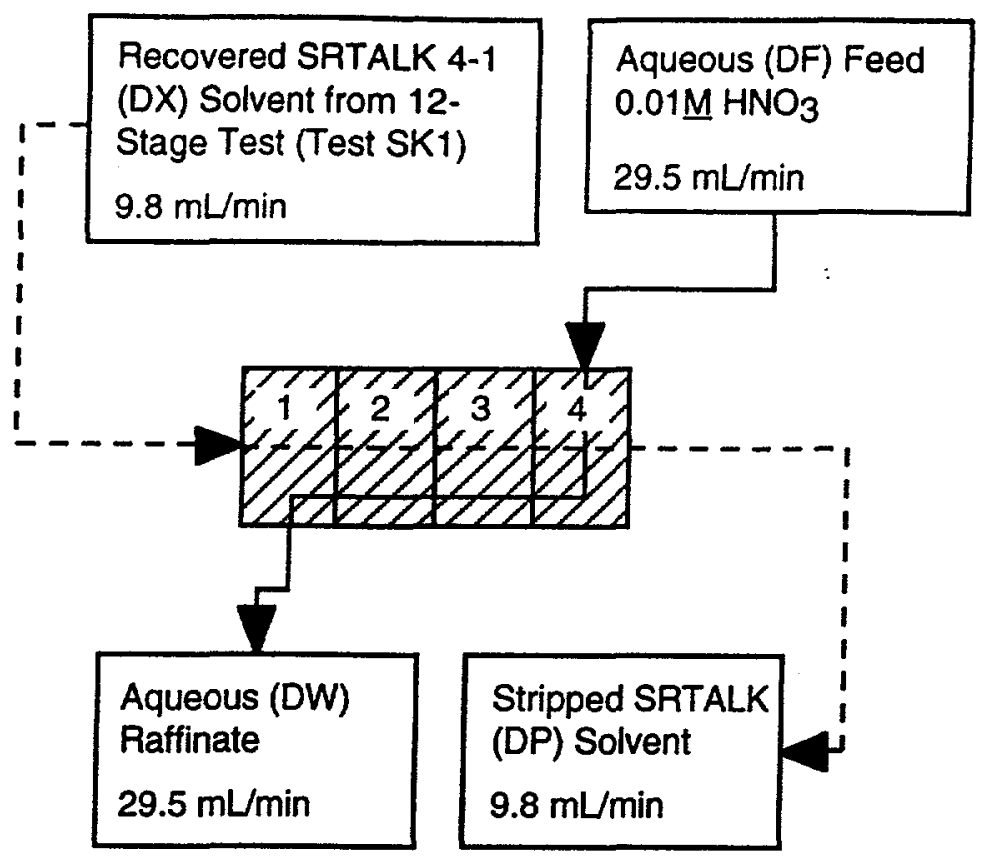

FIGURE 11. Flowsheet for Cleanup of SRTALK Solvent from Test SK1 (Test SK2).

\section{SRTALK FLOWSHEET TEST}

The SRTALK flowsheet shown in Fig. 7 was run in a minicontactor, test SK1, to demonstrate the operability of the SRTALK process. This test was very important because, if a solvent-extraction flowsheet can be run in a minicontactor, then it will also work in plant-scale process equipment. The only problem encountered during the test was the failure of the scrub-feed pump at $45 \mathrm{~min}$ into the $160 \mathrm{~min}$ test. When this happened, the test was stopped, the pump replaced, and the test restarted $35 \mathrm{~min}$ later. Since stopping the contactor and the feed pumps has only a small effect on the individual stage concentrations, this pump replacement early in the test should not affect the overall results. The test was very successful. Good hydraulic performance occurred in all 12 stages, the required D.F. of 6.4 for technetium removal from the other components was exceeded, and the concentration of technetium in the strip effluent showed a tenfold increase when compared with that in the extraction feed. The aqueous effluents, DW and EW, were hazy with no visible organic phase. Thus, the organic-phase carryover in these effluents was low, on the order of $20 \mathrm{ppm}$. 
Because the residence time of the organic phase was $20 \mathrm{~min}$ in the 12-stage contactor at the conditions of test SK1, the test time of $160 \mathrm{~min}$ (dictated by the solvent and technetium available) corresponded to a run of 8 residence times with respect to the organic phase. However, since 1.7 residence times are required to bring enough $\mathrm{Tc}$ into the contactor to create the final $\mathrm{Tc}$ concentration profile in the contactor stages if no Tc exits the contactor (this residence-time number gives a measure of the $\mathrm{Tc}$ pinching in the scrub section), the test time of $160 \mathrm{~min}$ corresponds to about 4.7 residence times with respect to the Tc. This should be enough time to allow Tc to be close to steady state at the end of test SK1. The measured Tc concentrations in the effluents and the equilibrated stage samples for the extraction and scrub sections at the end of the test are included in Fig. 12 along with the concentration profile calculated using the SASSE model. This model used the actual feed flow rates and concentrations, $0.25 \%$ other-phase carryover for $O$ in $A$ at each stage and $0.025 \%$ for $A$ in $O$ at each stage, and $100 \%$ stage efficiency in all stages except for the extraction section (stages 1-5), where the stage efficiency was $68 \%$. 


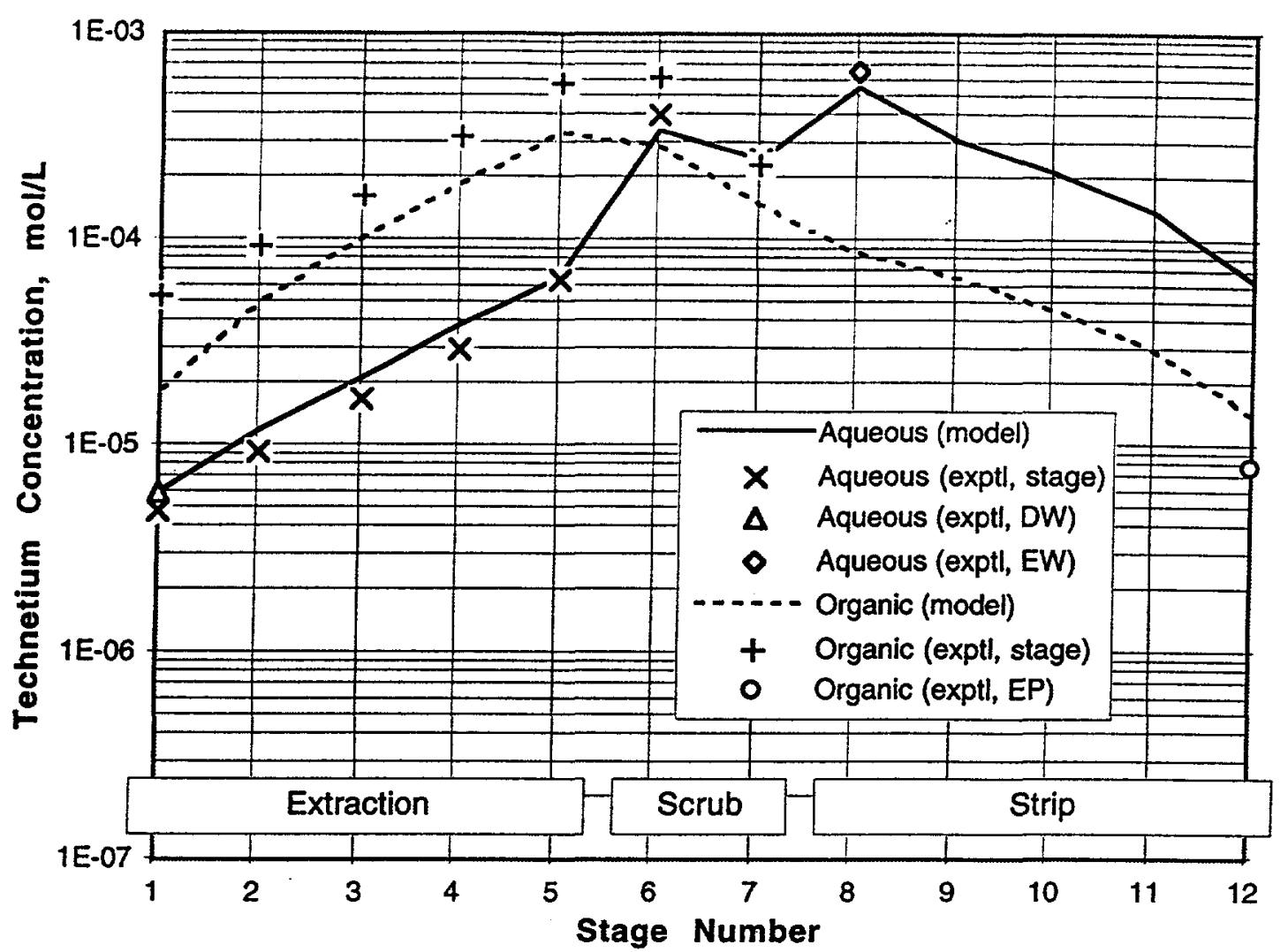

FIGURE 12. Concentration Profile for Technetium at the End of SRTALK Test SK1.

At the end of the test, the component concentrations in the EW effluent, given in Table 1, show how the other metal ions are very effectively removed from this effluent even as the Tc is being concentrated. The approach of $\mathrm{HNO}_{3}$ to its steady-state concentration in the EW effluent is shown in Fig. 13. The approaches of Tc to its steady-state concentration in the DW, EW, and EP effluents are shown in Figs. 14-16. At the end of the test, the Tc concentration, which was $64 \mu \underline{M}$ in the aqueous feed, had reached $630 \mu \underline{\mathrm{M}}$ in the strip effluent. At the same time, the Tc concentration was $5.9 \mu \mathrm{M}$ in the aqueous raffinate leaving the extraction section and $7.9 \mu \mathrm{M}$ in the organic product leaving the strip section. Thus, the overall material balance shows that the Tc recovered was $108 \%$ of that entering. 


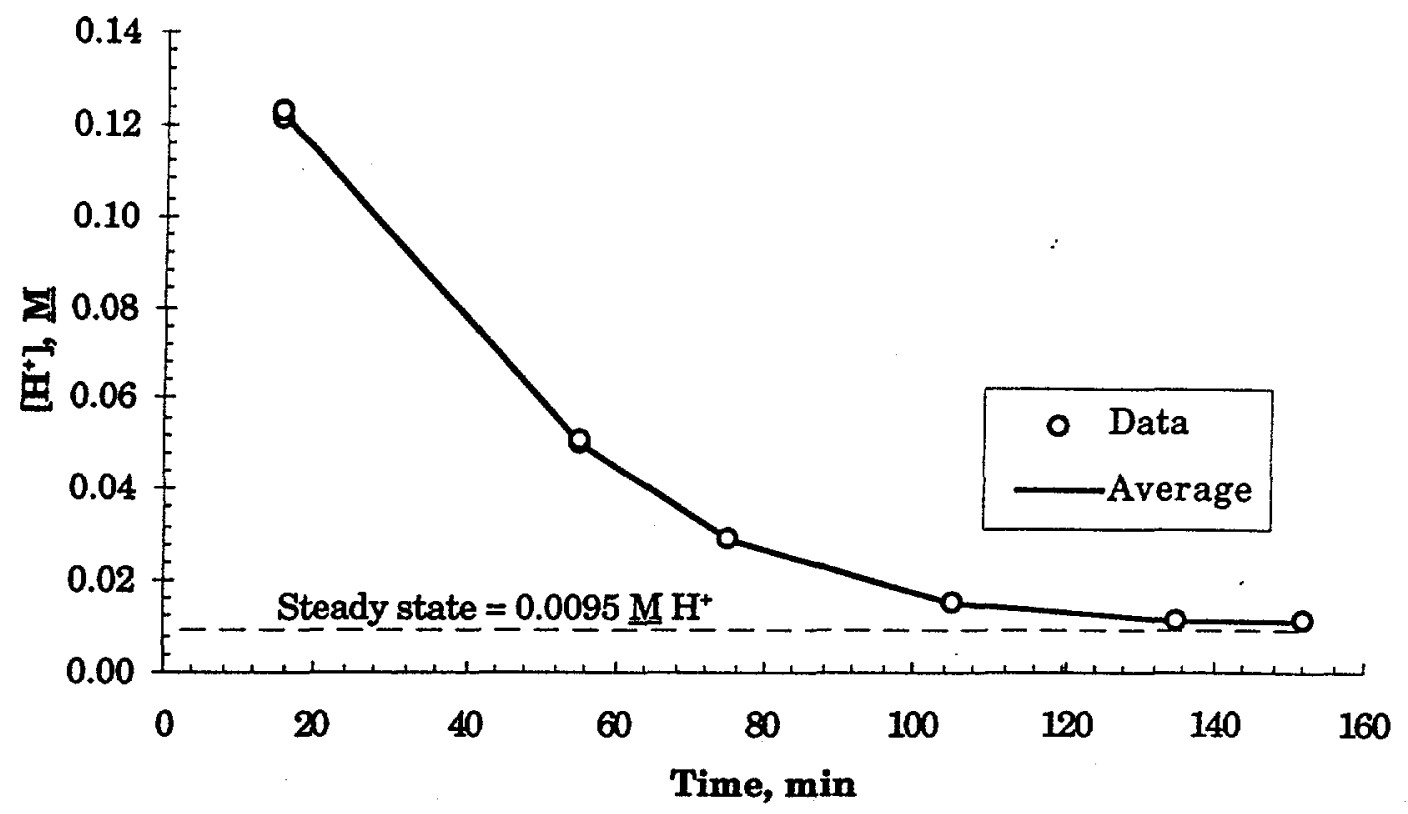

FIGURE 13. Variation of $\mathrm{HNO}_{3}$ with Time in the Aqueous Strip (EW) Effluent for SRTALK Test SK1.

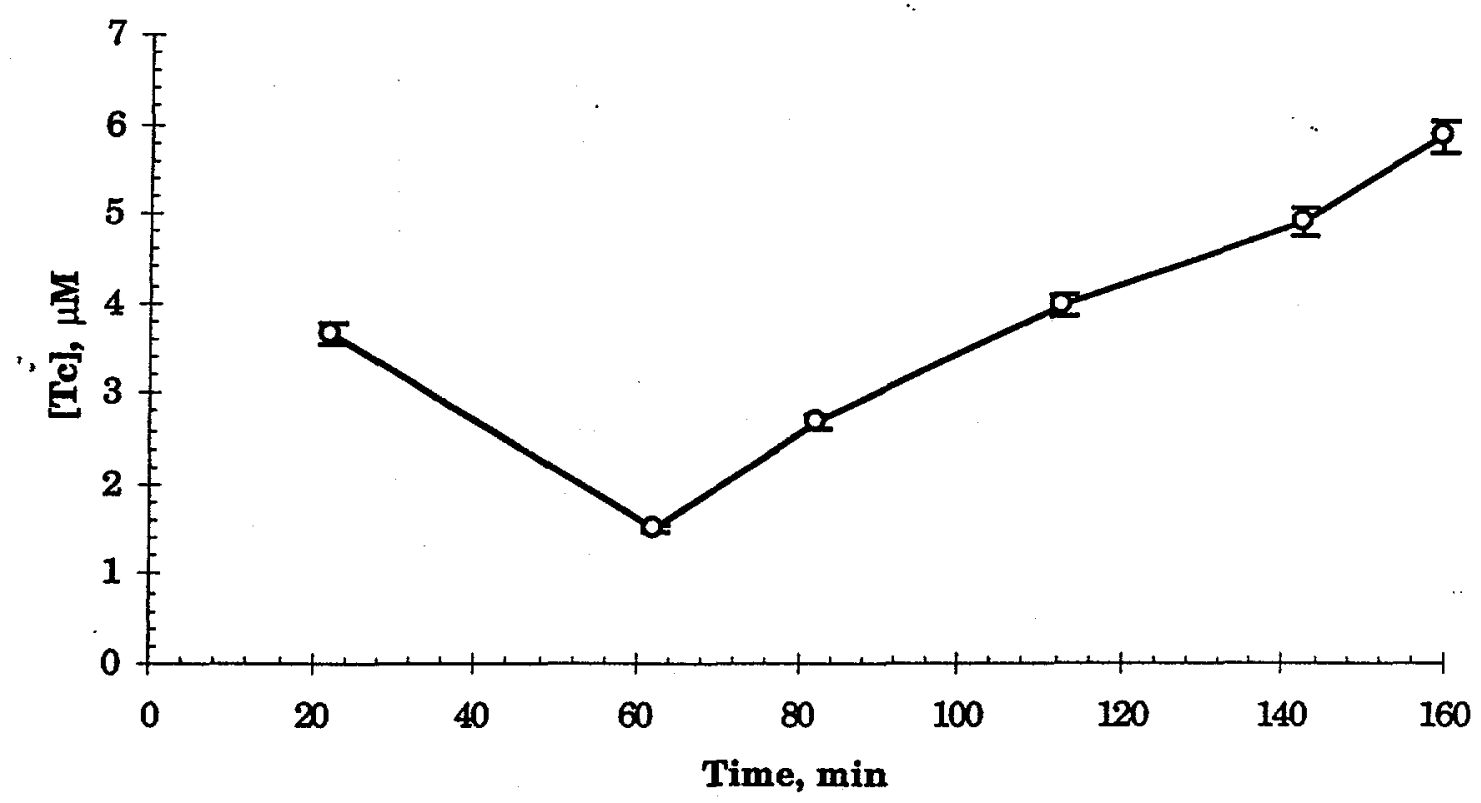

FIGURE 14. Variation of Tc with Time in the Aqueous (DW) Raffinate for SRTALK Test SK1. 


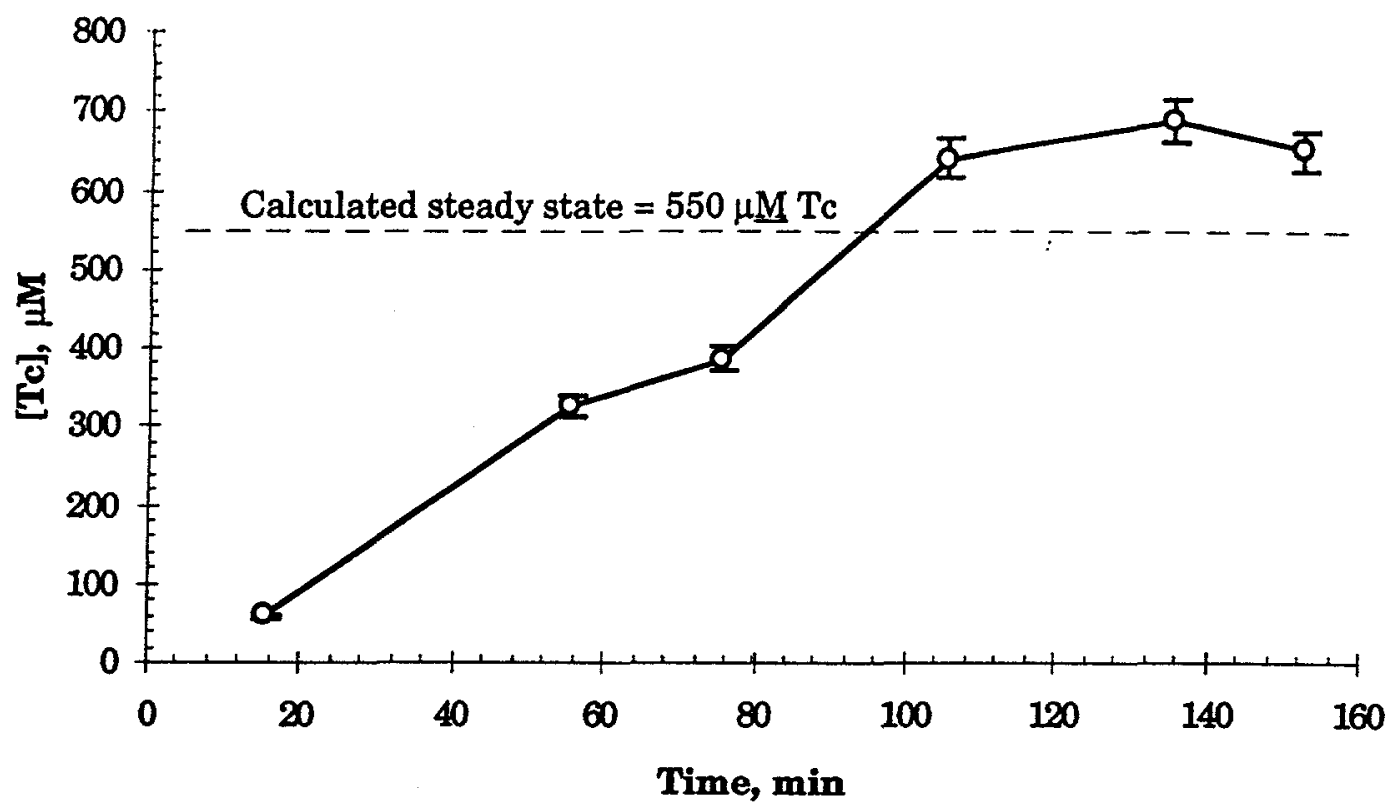

FIGURE 15. Variation of Tc with Time in the Aqueous Strip (EW) Effluent for SRTALK Test SK1.

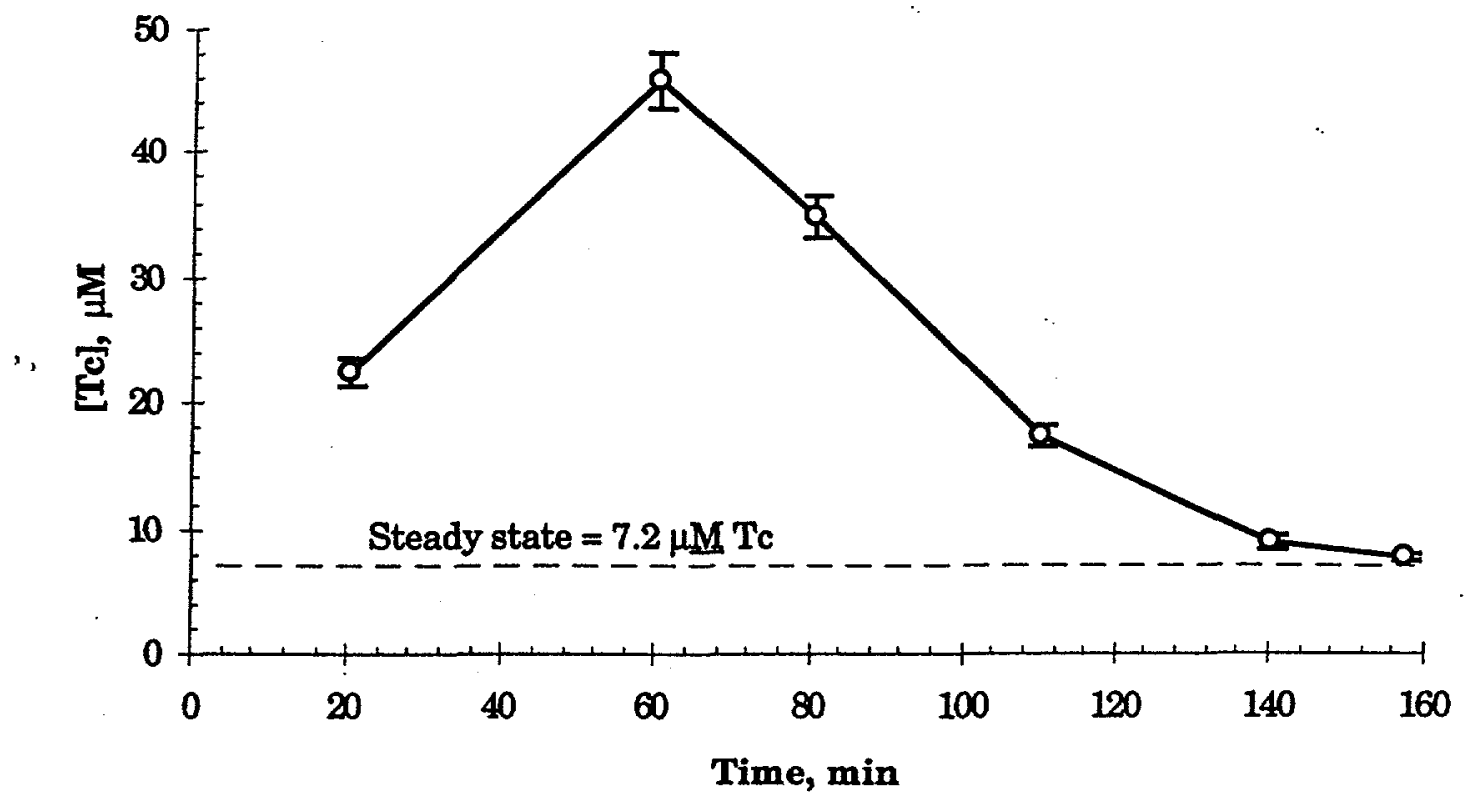

FIGURE 16. Variation of Tc with Time in the Organic (EP) Effluent for SRTALK Test SK1.

This slight excess in the $\mathrm{Tc}$ recovered is attributed to the higher than expected Tc concentration in the EW effluent. This excess Tc was caused by using 1.0 M $\mathrm{HNO}_{3}$ to flush the contactor stages prior to the test. Because of this flush, the 
residual acid in the strip section increased the acid concentration there significantly during startup. This condition raised $\mathrm{D}(\mathrm{Tc})$ significantly, allowing Tc to enter all the strip stages. This can be seen in Fig. 16, where the Tc concentration in the organic (EP) effluent first rises with time as more Tc reaches the strip section, then decreases towards its calculated steady-stage concentration as the excess acid is flushed out. One can also see the $\mathrm{HNO}_{3}$ concentration in the strip (EW) effluent decreasing with time to its steady-stage concentration in Fig. 13. Thus, as the acid level dropped in the strip section, the $\mathrm{Tc}$ in that section was flushed out and resulted in the slightly high Tc concentration in the EW effluent in the final approach of the process to steady-state conditions. A second effect of flushing with $1.0 \mathrm{M} \mathrm{HNO}_{3}$ was to leave some residual liquid in the stage drain lines. This excess acid caused the $D(T c)$ values in the stage samples taken from the strip stages at the end of the test to increase. When these stage samples were equilibrated, they were found to have $\mathrm{D}(\mathrm{Tc})$ values about 3.0 instead of around 0.2 , as expected.

\section{DISCUSSION}

This was a very successful test of the SRTALK process. We started with a data correlation for the key component, Tc, over the range of interest for the process and then used simple design rules along with SASSE analysis to develop the flowsheet. By first using the dispersion-number test to predict hydraulic performance, we greatly reduced the number of single-stage hydraulic performance tests required in the contactor. We were also reminded of the need to flush the contactor stages with an appropriate liquid before the test, so that the test results would not be affected by the residual solution that always remains. In most cases, this flush solution should be water. Four areas are discussed in more detail: (1) the approach to steady-state conditions, (2) the stage efficiency, (3) process economics, and (4) comparison of the results with simulated tank wastes to those with actual tank waste. 


\section{Steady State}

From Figs. 13-16, one can see that test SK1 was near to steady-state conditions at the end of the run. Because some pinching of Tc was expected in the scrub section, which would increase the time to reach steady state, each of these figures is reviewed to understand how close we really were to steady-state conditions. As seen in Fig. 13, the final $\mathrm{HNO}_{3}$ concentration of $0.0112 \mathrm{M}$ in the aqueous strip (EW) effluent appears to be close to steady-stage conditions. This was confirmed by extrapolating the $\mathrm{HNO}_{3}$ data for the $\mathrm{EW}$ effluent to steady state and obtaining a steady-state concentration of $0.0095 \underline{M}$. As seen in Fig. 15, the final Tc concentration of $630 \mu \mathrm{M}$ in the EW effluent appears to be close to, but above, the steady-stage concentration. As explained earlier, this was because Tc was being released by the strip section as the flowsheet approached its final steady-state condition. As shown in Table 1, the model value for the steady-state Tc concentration in the EW effluent is $550 \mu \mathrm{M}$. As shown in Fig. 16, the final Tc concentration of $7.9 \mu \underline{\mathrm{M}}$ in the organic (EP) effluent appears to be close to the steady-stage concentration. This was confirmed by extrapolating the Tc data for the EP effluent to a steady state and obtaining a steady-state concentration of $7.2 \mu \mathrm{M}$.

For the Tc concentration in the aqueous (DW) raffinate shown in Fig. 14, it is not clear what the steady-state concentration would have been. The final Tc concentration of $5.9 \mu \mathrm{M}$ was used to derive the stage efficiency of $68 \%$ in the extraction section. If the stage efficiency had been $90 \%$, the final Tc concentration would have been $1.2 \mu \underline{\mathrm{M}}$; if $100 \%, 0.4 \mu \mathrm{M}$. In general, the Tc concentration in the DW effluent and its variation with time probably reflect how the stage efficiency in the extraction section varies with time. This problem, and how to resolve it, are discussed next.

\section{Stage Efficiency}

As seen from the tests above, the stage efficiency is high, $>95 \%$, as long as the O/A flow ratio is 1.0 or higher for both single-stage and multistage tests. When the O/A flow ratio drops to 0.33 , the stage efficiency ranges from 68 to $92 \%$, 
as discovered for both single-stage and multistage tests here. In an acid-side test with $0.10 \mathrm{M}$ CE_Sr in 1-octanol, a 10-stage extraction section in a minicontactor with an O/A flow ratio of only 0.17 had a stage efficiency of only 60\% [LEONARD1997]. In a second acid-side test with 0.15M CE_Sr and 1.5 M TBP in Isopar ${ }^{\otimes} \mathrm{L}$, a 10-stage extraction section in a minicontactor was operated at an O/A flow ratio of 1.05 [LAW]. When the data from this test were analyzed, the stage efficiency in the extraction section was found to be $97 \%$.

Based on the data, solvents that contain CE_Sr (and perhaps other crown ethers or other large organic molecules that increase the viscosity of the organic phase) seem to exhibit lower stage efficiencies at low O/A flow ratios, 0.33 and less in the minicontactor. In this operating regime, the aqueous phase would be the continuous phase, and the organic phase would be the dispersed phase. With the greater viscosity of the organic phase, the organic droplets would be larger than those of the aqueous phase and harder to redisperse when they coalesce. Both of these conditions would cause the stage efficiency to be lower. The wide range for stage efficiency at low O/A flow ratios suggests that some major change in hydraulic performance is also occurring for the lower values, for example, the dispersion in the mixing zone might be experiencing a periodic loss of contact with the contactor rotor.

Low stage efficiencies caused by high dispersed-phase viscosity or changes in hydraulic performance can be corrected or compensated for in a number of ways. For example, more contactor stages could be added to compensate for lower stage efficiency. Alternatively, the problem can be corrected by increasing the mixing intensity in the annular mixing zone or increasing the residence time of the dispersion in the mixing zone. The residence time in the mixing zone can be increased by making changes to the rotor (increase inlet diameter) or stationary housing (use fewer bottom vanes or more space under the rotor body or both). The mixing intensity can be increased by decreasing the annular gap, increasing the rotor speed, or adding vertical vanes to the rotor surface and vertical baffles to the stationary housing [CHOW]. In fact, just using a larger contactor may solve the problem since larger contactors typically have greater mixing intensity 
(energy/unit volume) in the annular mixing zone and greater dispersion height. For a typical 2-cm contactor, the estimated dispersion height is $3 \mathrm{~mm}$ and the mixing intensity is $86 \mathrm{~kW} / \mathrm{m}^{3}$; for a typical $4-\mathrm{cm}$ contactor, $26 \mathrm{~mm}$ and $125 \mathrm{~kW} / \mathrm{m}^{3}$; for a typical $25-\mathrm{cm}$ contactor, $230 \mathrm{~mm}$ and $445 \mathrm{~kW} / \mathrm{m}^{3}$.

\section{Process Economics}

An economic analysis was done for the SRTALK process based on the successful test in the centrifugal contactor. In this analysis, a solvent-recovery system was included so that solvent losses are very small. For comparison with the SRTALK process, the economic analysis included an alternative ion-exchange (IX) system, Reillex ${ }^{\mathrm{TM}}-\mathrm{HPQ}$ resin in packed columns. Both analyses assumed an aqueous (DF) feed rate of $100 \mathrm{~L} / \mathrm{min}$ of tank supernate to the process with operation 24 hours a day for 300 days a year. These estimates (see Table 2) show that the capital costs for the SRTALK process are greater, $\$ 13.32 \mathrm{M}$ compared with $\$ 8.08 \mathrm{M}$ for the packed columns. However, the estimates for the annual operating costs (see Table 3 ) show that those for SRTALK process are less, $\$ 1.28 \mathrm{M}$ compared with $\$ 3.54 \mathrm{M}$ for the packed columns. In addition, the SRTALK should have additional downstream cost benefits, such as a reduced number of glass logs generated for waste disposal, since its technetium effluent has such low concentrations of the other metal ions in the aqueous feed. This technetium effluent will also be free of any chemicals (e.g., tin, ethylene diamine) required to strip Tc from the Reillex ${ }^{\mathrm{TM}}-\mathrm{HPQ}$ column. Also, organic complexants such as ethylene diamine would likely need to be removed before vitrification can be performed; a disadvantage of using the Reillex ${ }^{\mathrm{TM}}-\mathrm{HPQ}$ resin. 
TABLE 2. Estimated Capital Costs for SRTALK Using Centrifugal Contactors and Ion Exchange Using Columns of Reillex ${ }^{\mathrm{TM}}-\mathrm{HPQ}$ Resin

\begin{tabular}{|c|c|c|}
\hline & \multicolumn{2}{|c|}{ Costs, $\$ \mathrm{M}$} \\
\hline & $\begin{array}{c}\text { SRTALK } \\
\text { w/Contactors }\end{array}$ & $\begin{array}{l}\text { IX Columns } \\
\text { w/Adsorbent }\end{array}$ \\
\hline SRTALK Solvent & 1.69 & \\
\hline Contactor Stages (installed cost) & 4.47 & \\
\hline Solvent Recovery Unit (installed cost) & 0.15 & \\
\hline Reillex ${ }^{\mathrm{TM}}-\mathrm{HPQ}$ Resin & & 0.50 \\
\hline Columns (installed cost) & & 0.78 \\
\hline Evaporator (installed cost) & 0.33 & 0.33 \\
\hline Balance of Equipment (installed cost) & 6.68 & 6.46 \\
\hline Total Capital Cost & 13.32 & 8.07 \\
\hline
\end{tabular}

TABLE 3. Estimated Operating Costs for SRTALK Using Centrifugal Contactors and Ion Exchange Using Columns of Reillex ${ }^{\mathrm{TM}}-\mathrm{HPQ}$ Resin

\begin{tabular}{rcc} 
& \multicolumn{2}{c}{ Costs, $\$ \mathrm{M} / \mathrm{yr}$} \\
\cline { 2 - 3 } & SRTALK & IX Columns \\
w/Contactors & w/Adsorbent \\
\cline { 2 - 3 } Personnel & 0.60 & 0.60 \\
Electrical & 0.44 & 0.09 \\
Steam Power & 0.23 & 0.23 \\
SRTALK Solvent & 0.01 & 2.62 \\
n (use 11 times) & & 3.54
\end{tabular}

These economic calculations assume that all radioactive operations and radioactive solution storage will be done in a shielded-cell facility. They do not take into account radiation damage to either the solvent or the resin. In practice, such damage would cause some increase in the annual operating cost for both processes. The total SRTALK solvent in the process is 5.7 times that in the contactors. The SRTALK solvent recovery system would reduce the solvent lost by a factor of 1000 . Without this system, the annual operating cost for SRTALK solvent could be as much as $\$ 12$ million per year ( $\$ \mathrm{M} / \mathrm{yr})$. Based on information in [SCHROEDER], the number of bed volumes before an IX column is loaded with Tc drops from 57 to 23 in eleven cycles. Our calculation of operating cost assumed that one can get 11 or more good resin cycles with 60 bed volumes of feed for each cycle by using an upward flow of the fluid eluting the Tc from the bed. If one 
could get 80 resin cycles with 60 bed volumes for each cycle of the resin, then annual operating costs for both systems would be the same.

Discussed next are some details of the flowsheet on which the economic estimates are based. The 24-stage $30-\mathrm{cm}$ contactor alone costs $\$ 1.2 \mathrm{M}$; as installed in a shielded-cell facility, it costs $\$ 4.5 \mathrm{M}$. Four of the stages are for solvent recovery. Extraction and strip each have nine stages so that the SRTALK flowsheet will be very resistant to process upsets and fluctuations in the DF feed concentration. In addition, these stages give the potential for higher D.F.'s and further increases in Tc concentration in the $\mathrm{EW}$ effluent. The inventory for the SRTALK solvent is $509 \mathrm{~L}$ in the contactor and $2400 \mathrm{~L}$ in the feed/recycle tank for a total solvent inventory of $2909 \mathrm{~L}$. The solvent cost is $\$ 582 / \mathrm{L}$ with $99.92 \%$ of this cost coming from the CE_Sr. The cost of installing the units in a shielded-cell facility has been included in the capital cost. The cost of building such a facility has not been included. This is very site specific, and many sites may want to use an existing facility. For the contactors, the hot area, cold area, and total area are 4900,3000 , and $7900 \mathrm{sq} \mathrm{ft}\left(455,279\right.$, and $\left.734 \mathrm{~m}^{2}\right)$, respectively; for ion exchange, $3300,2600,5900 \mathrm{sq} \mathrm{ft}\left(307,241\right.$, and $\left.548 \mathrm{~m}^{2}\right)$.

During the test SK1, both the DW and EW effluents were hazy. Based on the single-stage hydraulic-performance tests, this haziness corresponds to about 20 ppm of solvent. If this dispersed solvent were allowed to exit with the aqueous effluents, it would add $0.60 \$ \mathrm{M} / \mathrm{yr}$ to the operating costs for the SRTALK process. In addition, if CE_Sr dissolves in the aqueous phases to the extent of $1 \mathrm{ppm}$ (in the middle of the expected range based on very limited data), this dissolved crown ether loss would add an additional $1.56 \$ \mathrm{M} / \mathrm{yr}$ to the operating costs for the SRTALK process. Finally, if the DW effluent became cloudy (since the flow rate for the DW effluent is 12 times that for the EW effluent, a high solvent loss in DW effluent would have the biggest effect), this would correspond to about $400 \mathrm{ppm}$ of solvent and would add $12.07 \$ \mathrm{M} / \mathrm{yr}$ to the operating costs for the SRTALK process. Thus, because solvent loss can be so important, a solvent recovery system was added to the SRTALK process and included in the economic analysis. Since it reduces losses of dispersed solvent and dissolved crown ether by a factor of 1000 , 
the solvent loss rate for the worst-case scenario of $400 \mathrm{ppm}$ would drop from 20,700 $\mathrm{L} / \mathrm{y}$ to $21 \mathrm{~L} / \mathrm{y}$.

\section{Actual Tank Waste}

To evaluate SRTALK operation with actual tank waste, we conducted two batch tests at Pacific Northwest National Laboratory (PNNL) using an O/A volume ratio of 1.0 with a SRTALK solvent (4-2) consisting of 0.04M CE_Sr and 1.8 $\mathrm{M}$ TBP with the rest Isopar ${ }^{\oplus} \mathrm{M}$. The aqueous feed was actual double-shell slurry feed (DSSF) waste consisting of $70 \%$ by volume from tank AW-101, 20\% from AP-106, and 10\% from AP-102. In the extraction test, these two phases where contacted and $\mathrm{D}(\mathrm{Tc})$ was measured. In the strip test, the loaded solvent was contacted with water and $\mathrm{D}(\mathrm{Tc})$ was measured. This test was compared with an identical test at ORNL using a DSSF simulant called DSSF-7. The composition

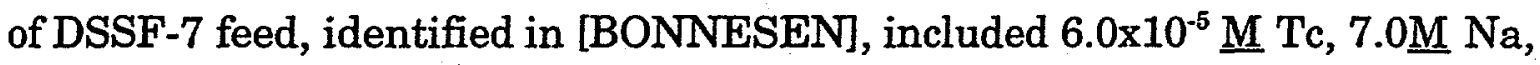
$0.945 \mathrm{M} \mathrm{K}, 0.721 \mathrm{M} \mathrm{Al}$, and 3.52M NO $\mathrm{NO}_{3}$. The composition of DSSF feed had a similar amount of $\mathrm{Tc}, 8.9 \mathrm{M} \mathrm{Na}, 0.92 \mathrm{M} \mathrm{K}, 0.80 \mathrm{M} \mathrm{Al}$, and an undetermined amount of $\mathrm{NO}_{3}$. Based on the nitrate analysis for tank 222-S normalized to the Na concentration in the DSSF feed, the nitrate concentration is expected to be around 2.5M. The $\mathrm{D}(\mathrm{Tc})$ values for both tests are given in Table 4.

TABLE 4. Comparison of Batch Tests with Simulated and Actual Waste

\begin{tabular}{|c|c|c|c|c|c|c|}
\hline \multirow[b]{3}{*}{ Aqueous Phase } & \multicolumn{6}{|c|}{$\mathrm{D}(\mathrm{Tc})$} \\
\hline & \multicolumn{3}{|c|}{ Extraction } & \multicolumn{3}{|c|}{ Strip } \\
\hline & Meas. & Model & $\begin{array}{l}\text { Model/ } \\
\text { Meas. }\end{array}$ & Meas. & Model & $\begin{array}{l}\text { Model/ } \\
\text { Meas. }\end{array}$ \\
\hline $\begin{array}{l}\text { DSSF-7 (simulant; test } \\
\text { done at ORNL) }\end{array}$ & 8.6 & 10.1 & 1.17 & 0.27 & 0.30 & 1.11 \\
\hline $\begin{array}{l}\text { DSSF (70\% AW-101, } 20 \% \\
\text { AP-106, } 10 \% \text { AP-102; test } \\
\text { done at PNNL) }\end{array}$ & 9.3 & 10.9 & 1.17 & 0.29 & 0.30 & 1.03 \\
\hline
\end{tabular}

Also shown in Table 4 are the D(Tc) values calculated using Eqs. (1-7) and the SASSE worksheet. In making this comparison, we assume that the change in diluent, from Isopar ${ }^{\oplus} \mathrm{L}$ for the model data to Isopar ${ }^{\circ} \mathrm{M}$ for the tests in Table 4, will have little effect on $\mathrm{D}(\mathrm{Tc})$. Other ORNL tests comparing Isopar ${ }^{\oplus} \mathrm{L}$ with Isopar ${ }^{\oplus} \mathrm{M}$ 
show that $\mathrm{D}(\mathrm{Tc})$ values are 5 to $10 \%$ higher when Isopar ${ }^{\otimes} \mathrm{L}$ is the diluent. The ORNL model values are reported as calculated. Using the ratio of $\mathrm{D}($ model $) / \mathrm{D}$ (meas) for $\mathrm{Tc}$ in the extraction test at ORNL, the concentration of $\mathrm{NO}_{3}$ for the PNNL test was varied until it gave the same ratio. (That this ratio is significantly greater than 1.0 may be the result of either the model, which does not account for the competition of $\mathrm{AlO}_{2}^{-}$with $\mathrm{TcO}_{4}^{-}$, only $\mathrm{NO}_{3}^{-}$with $\mathrm{TcO}_{4}$, or the diluent or both.) This $\mathrm{NO}_{3}$ concentration, $4.92 \mathrm{M}$, was then used to calculate $\mathrm{D}(\mathrm{Tc})$ for the strip test at PNNL. These tests show good agreement between $\mathrm{D}(\mathrm{Tc})$ for the model and the experimental data. In addition, they show that technetium in actual tank waste extracts and strips in the same way as it does in the simulant.

\section{CONCLUSIONS}

The SRTALK process for the alkaline-side removal and recovery of technetium from nuclear waste tanks was taken from a batch extraction process performed in test tubes to a continuous countercurrent process. Since the continuous countercurrent process was demonstrated in a minicontactor, one can be reasonably certain that the SRTALK process will also work in plant-scale process equipment. The demonstration was very successful, with all process goals being met. These goals included exceeding the required D.F. of 6.4 for technetium removal from the other components, and showing a ten-fold increase in the concentration of technetium in the strip effluent from that in the extraction feed.

This paper shows how engineering development and testing were used to achieve this very successful test of the SRTALK process. The work started with correlating the data for the key component, Tc, over the range of interest for the process and then using simple design rules along with SASSE analysis to develop the flowsheet. By first using the dispersion-number test to predict hydraulic performance, we were able to greatly reduce the number of single-stage hydraulic-performance tests required in the contactor. Mass-transfer tests showed that stage efficiency, which was normally $>95 \%$, dropped when $\mathrm{Tc}$ was extracted at low O/A flow ratios in the minicontactor with a solvent containing a 
crown ether. At low O/A flow ratios, the stage efficiency was found to range from 68 to $92 \%$. A variety of ways to compensate for or correct this situation in the future are given. Batch tests with actual tank waste at PNNL showed that technetium in the tank waste extracts and strips in the same way as it does in a simulated waste used at ORNL. When an economic analysis of the SRTALK process was done and compared with a competing ion-exchange process, it was found that the capital costs for the SRTALK process are greater, but the annual operating costs are less. While more work will be needed to compare processes and establish the most appropriate process for removing technetium from nuclear tank wastes, this work establishes that the SRTALK process will work well and may also be the most economical process when the overall task of converting nuclear tank waste into glass logs is considered.

\section{ACKNOWLEDGMENTS}

This work was supported by the U.S. Department of Energy through Efficient Separations and Processing Crosscutting Program, Office of Science and Technology, Office of Environmental Management under Contract W-31-109-Eng38 with Argonne National Laboratory managed by the University of Chicago, Contract DE-AC05-96OR22464 with Oak Ridge National Laboratory managed by Lockheed Martin Energy Research Corp., and Contract DE-AC06-76RLO 1830 with Pacific Northwest National Laboratory.

\section{REFERENCES}

\section{BLANCHARD}

D. L. Blanchard, Jr., G. N. Brown, S. D. Conradson, S. K. Fadeff, G. R. Golcar, N. J. Hess, G. S. Klinger, and D. E. Kurath, Technetium in Alkaline, High-Salt, Radioactive Tank Waste Supernate: Preliminary Characterization and Removal, Pacific Northwest National Laboratory Report PNNL-11386, Richland, WA (1997). 


\section{BONNESEN}

P. V. Bonnesen, B. A. Moyer, D. J. Presley, V. S. Armstrong, T. J. Haverlock, R. M. Counce, and R. A. Sachleben, Alkaline-Side Extraction of Technetium from Tank Waste using Crown Ethers and Other Extractants, Oak Ridge National Laboratory Report ORNL/TM-13241, Oak Ridge, TN (1996).

\section{CHOW}

L. S. Chow and R. A. Leonard, "Centrifugal Pyrocontactor," U.S. Patent 5,254,076, October 19, 1993.

LAW

J. D. Law, D. J. Wood, L. G. Olson, T. A. Todd, Demonstration of a SREX Flowsheet for the Partitioning of Strontium and Lead from Actual ICPP Sodium-Bearing Waste, Idaho National Engineering and Environmental Laboratory Report INEEL/EXT-97-00832, Idaho Falls, ID (1997).

\section{LEONARD-1987}

R. A. Leonard, "Use of Electronic Worksheets for Calculation of Stagewise Solvent Extraction Processes," Sep. Sci. Technol. 22, 535-556 (1987).

\section{LEONARD-1994}

R. A. Leonard and M. C. Regalbuto, "A Spreadsheet Algorithm for Stagewise Solvent Extraction," Solvent Extr. and Ion Exch. 12, 909-930 (1994).

\section{LEONARD-1995}

R. A. Leonard, "Solvent Characterization using the Dispersion Number," Sep. Sci. Technol. 30, 1103-1122 (1995).

\section{LEONARD-1997}

R. A. Leonard, D. B. Chamberlain, and C. Conner, "Centrifugal Contactors for Laboratory-Scale Solvent Extraction Tests," Sep. Sci. Technol. 32, 193-210 (1997).

\section{LEONARD-1998}

R. A. Leonard and E. P. Horwitz, "Design Rules for Solvent Extraction," Solvent Extr. Ion Exch. (To be submitted for publication).

\section{ROBBINS}

L. A. Robbins, "Liquid-Liquid Extraction", Section 15 in R. H. Perry, D. W. Green, and J. O. Maloney, editors, Chemical Engineers' Handbook, 6th ed, McGraw-Hill, New York (1984). 


\section{SCHROEDER}

N. C. Schroeder, S. Radzinski, K. R. Ashley, J. Ball, F. Stanmore, and G. Whitener, Technetium Partitioning of the Hanford Tank Waste Remediation System: Sorption of Technetium from DSS and DSSF-7 Waste Simulants Using Reillex ${ }^{\mathrm{TM}}$-HPQ Resin, Los Alamos National Laboratory Report LA-UR95-40, Los Alamos, NM (1995). 